\title{
أسس النقل الحضري المستدام للمدينة العربية الجديدة
}

\author{
م/علي محمود حاتم الصرفي

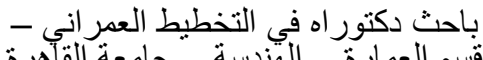 \\ قسم العمارة - القزنسانة - جامعة القآهرة \\ Sarafy100@gmail.com
}

\author{
دا دإنجي محمد البرملجي

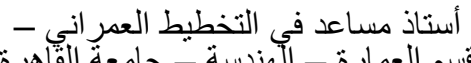 \\ I_barmelgy@yahoo.com
}

الملخص

أصبحت الاستدامة كمفهوم عصري تمثل حاجة ماسة لحل كافة الإشكاليات المعاصرة و أهمها المشاكل الحضرية للمدن وتخطيطها

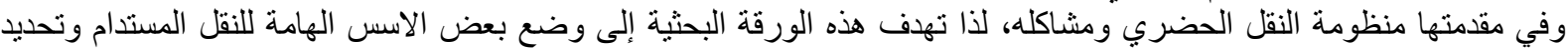
أولوياته للمدينة العربية الجديدة لتنتاسب مع خصوصئ وميتها ومشاكلها.

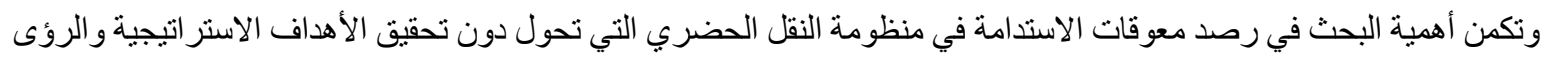

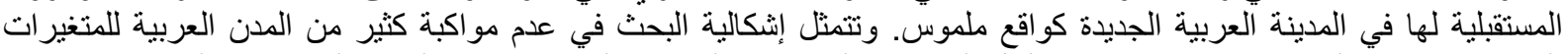

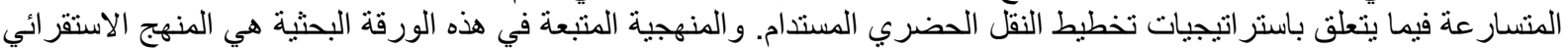
التحليلي المقارن.

وتتتاول الورقة البحثية المفاهيم الأساسية للاستدامة ومعايير ها، والتحديات التي تو اجه منظومة النقل الحضري في تخطيط المدينة

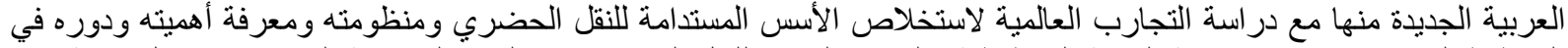
التخطيط المستدام ومن ثم مر اجعة الرؤية التخطيطية و الوضع الر اهن للنقل الحضري في المدن المئة المصرية الجديدة من خلال مدينة برج العرب الجديدة كحالة در اسية.

الكلمات الدالة: النقل الحضري ـ الاستدامة ـ المدينة العربية ـ تخطيط الددن الجديدة.

ا مقدمة

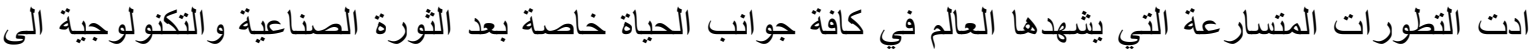

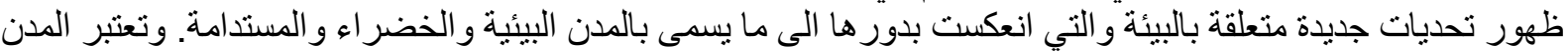

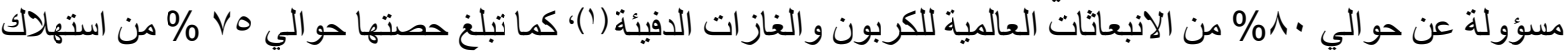

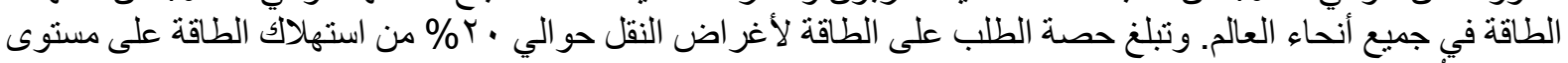

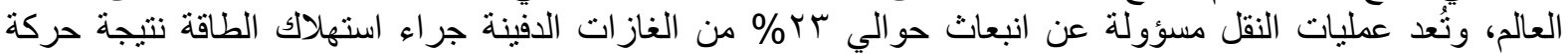

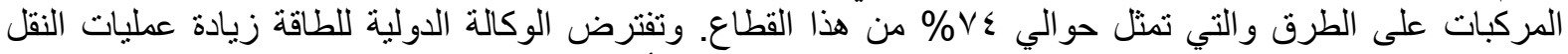

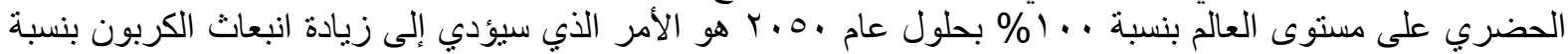

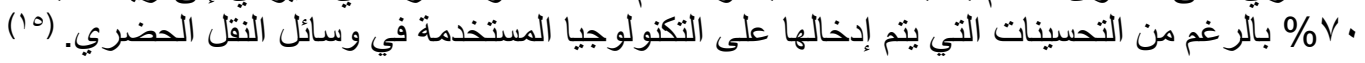

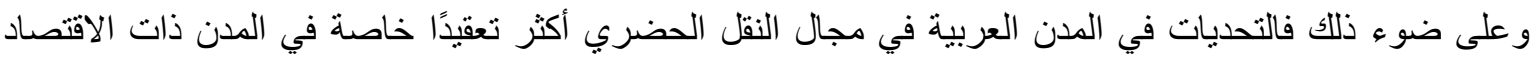

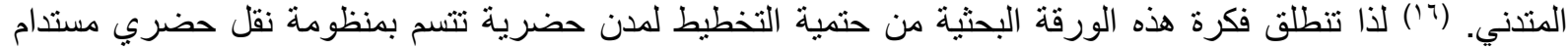

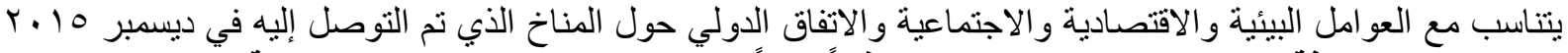

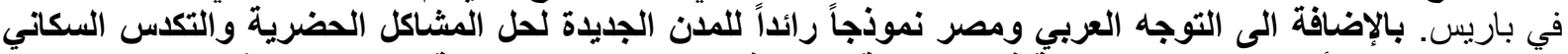

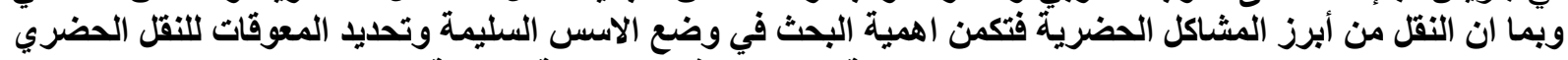

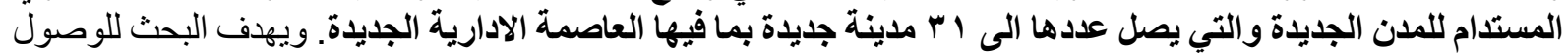

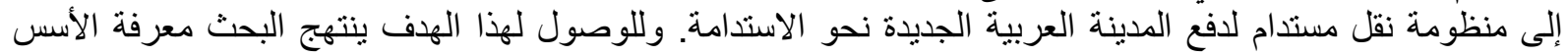

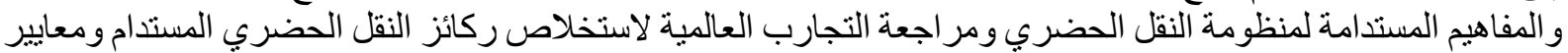

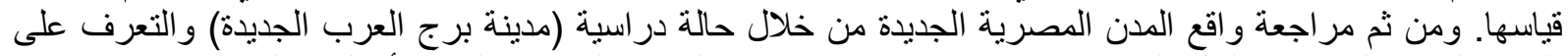
الواقع الراهن لمنظومة النقل الحضري ومقارنته بما هو مخطط له في المخطط العام الأصلي والمخطط الاستراتيجي

وتعد المشكلة الرئيسية هي و اقع منظومة النقل الحضري الحالي للمدن العربية الجديدة فهناك فجوة كبيرة بين الوضع الر اهن لمنظومة النقل الحضري وبين النقئ هي واعل المستدام العالمي.

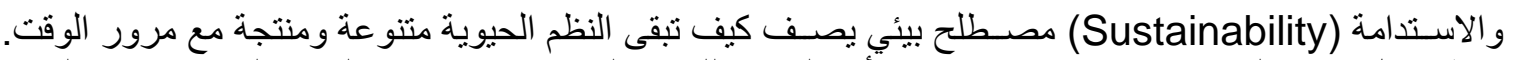

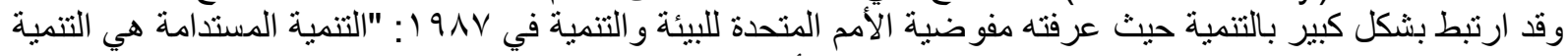
التي تفي باحتياجات الوقت الحاضـر دون المسـاس بقدرة الأجيال المقبلة على تلبية احتياجاتها الخاصـة. (؟) ويمكن تعريفه 


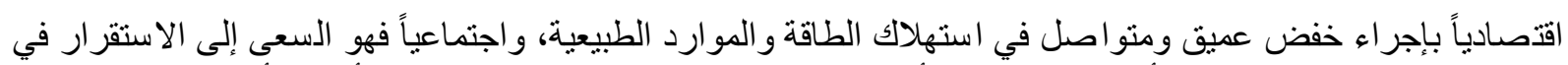

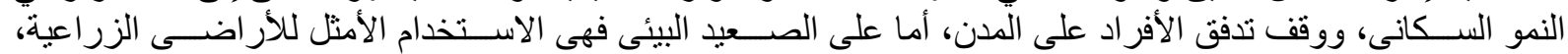

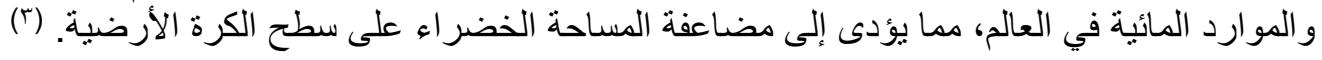

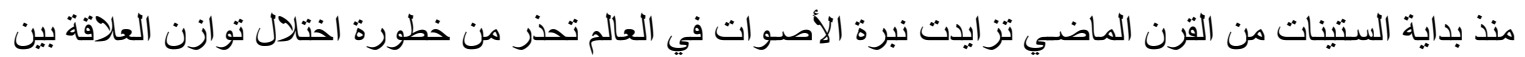

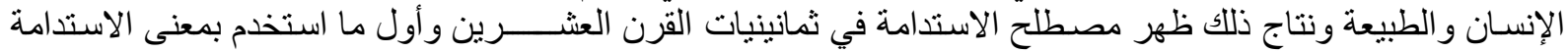

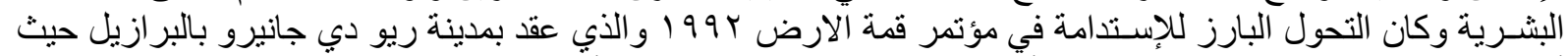

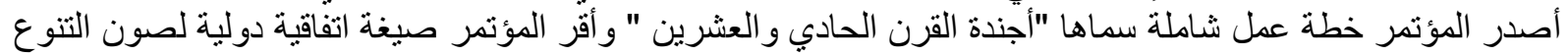

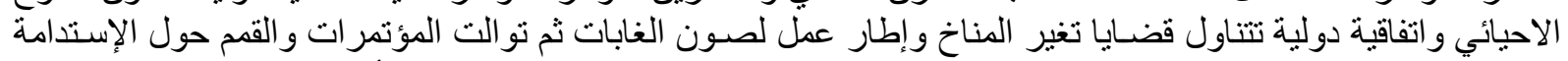

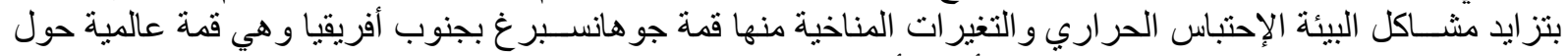

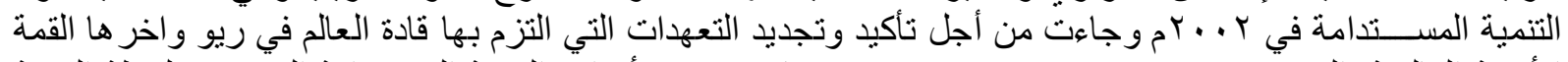

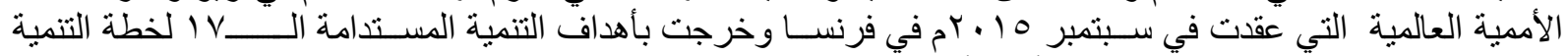

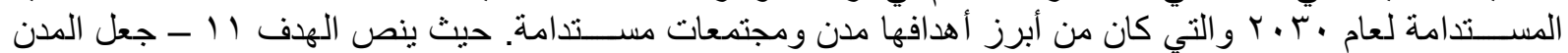

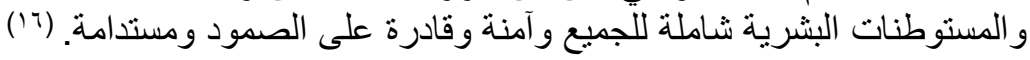

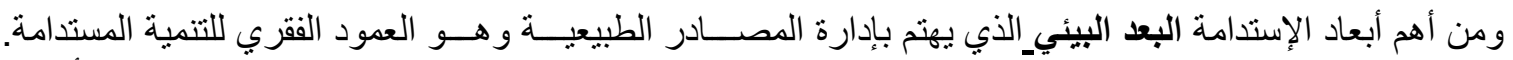

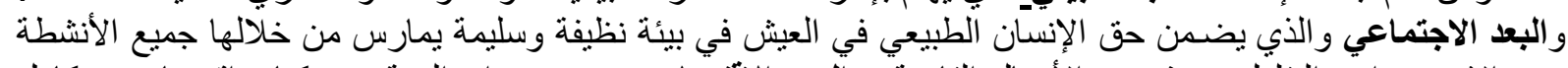

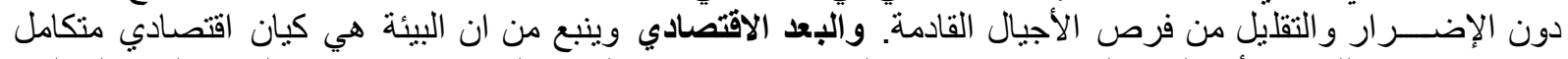

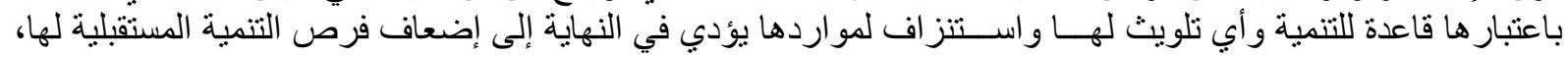

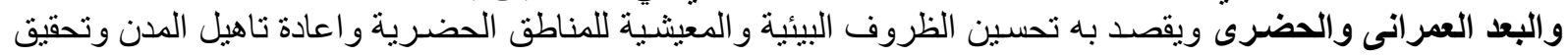

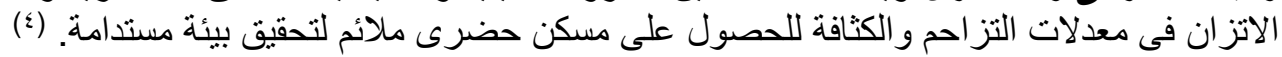

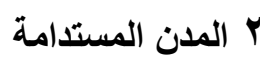

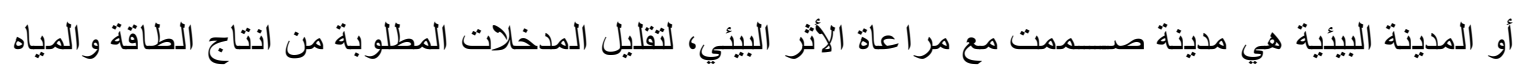

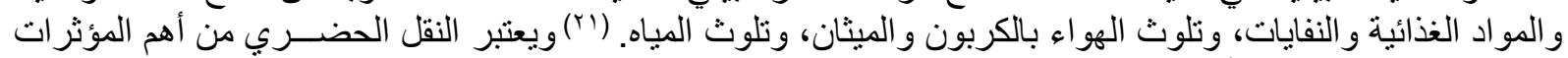

شكل (1) العناصر الأساسية للمدينة المستدامة

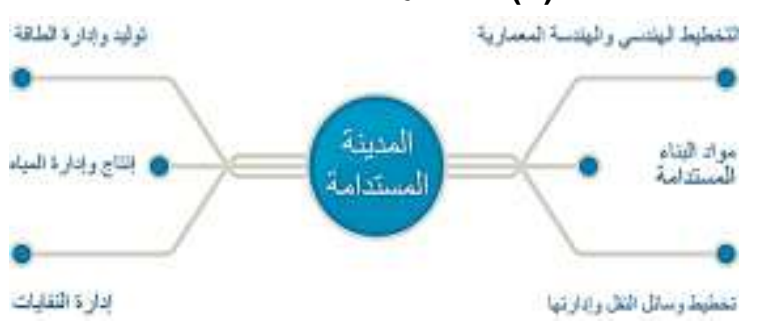

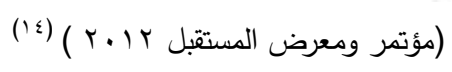

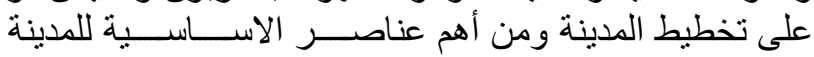

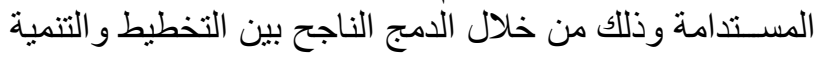

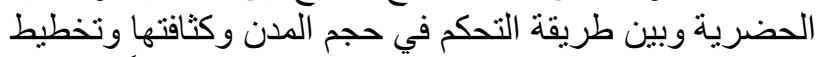

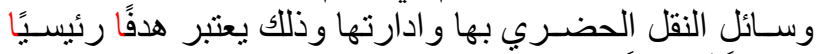

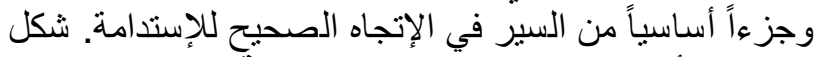

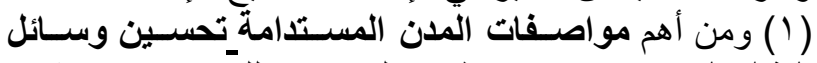

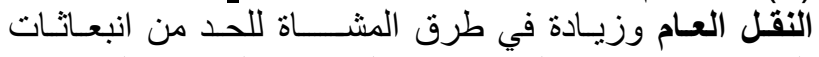

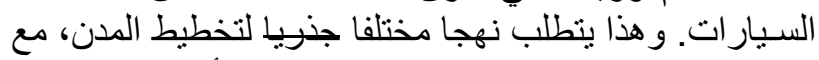

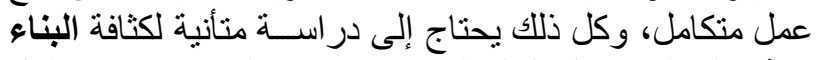

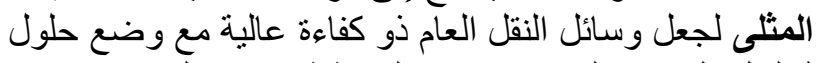

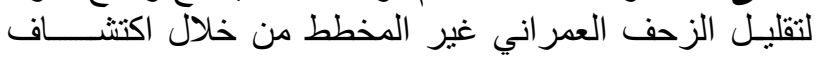

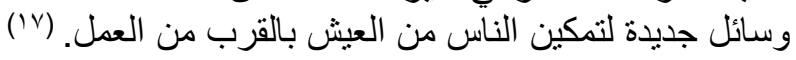

r التخطيط العمراني المستدام

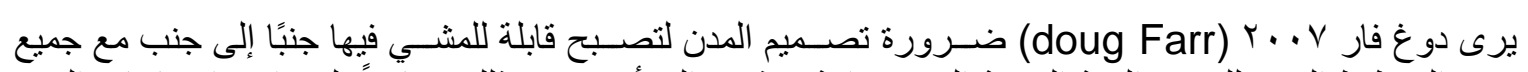

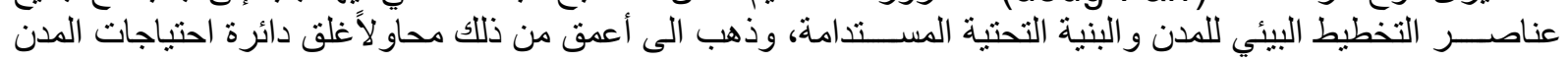

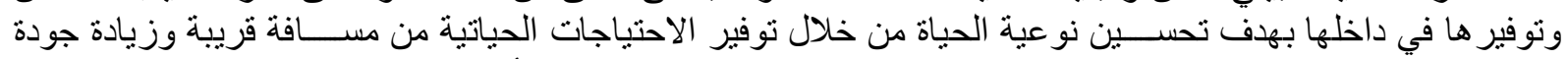

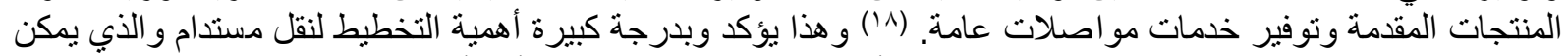

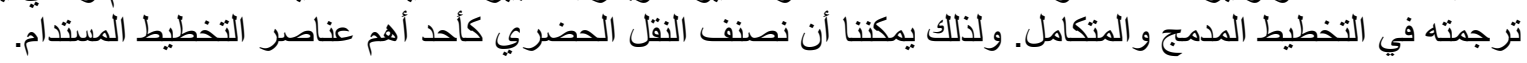

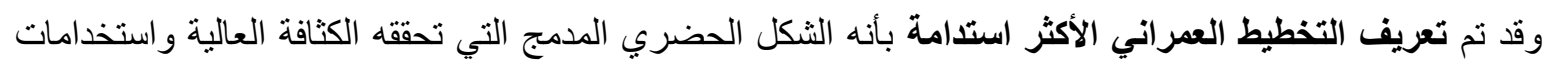

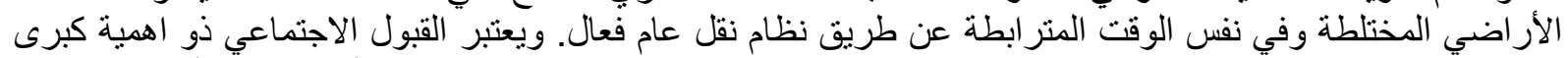

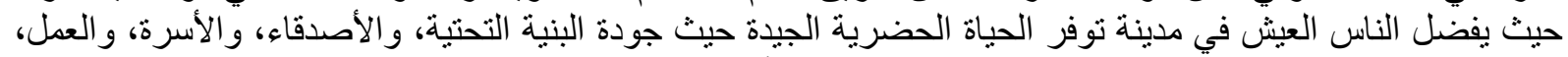

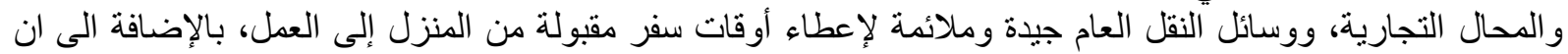
تكون مدن صديقة للأطفال، والمدارس هي ضمن مسافة المشي من المناطق السكنية. (') 


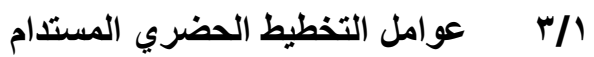

من أهم استر اتيجيات التخطيط الدضري المستدام تقليل الطاقة المستنفذة في التنقل وداخل المباني (ادارة الطاقة و النقل

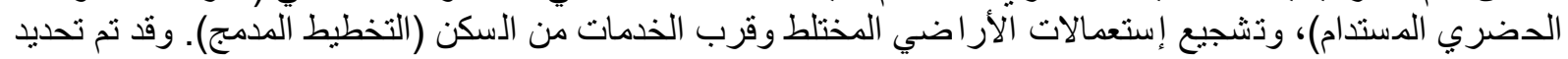

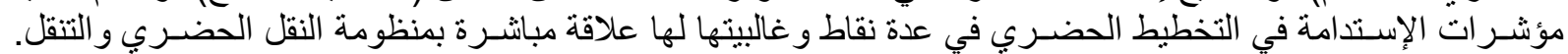

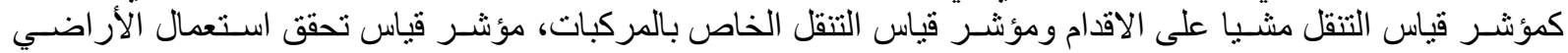

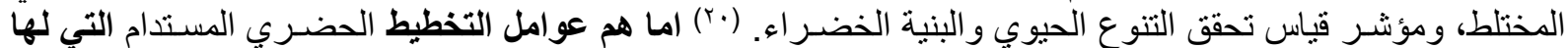
علاقة مباشرة بالنقل الحضري (التخطيط المدمج والكثافة العالية والتشكيل العمراني المستدام)

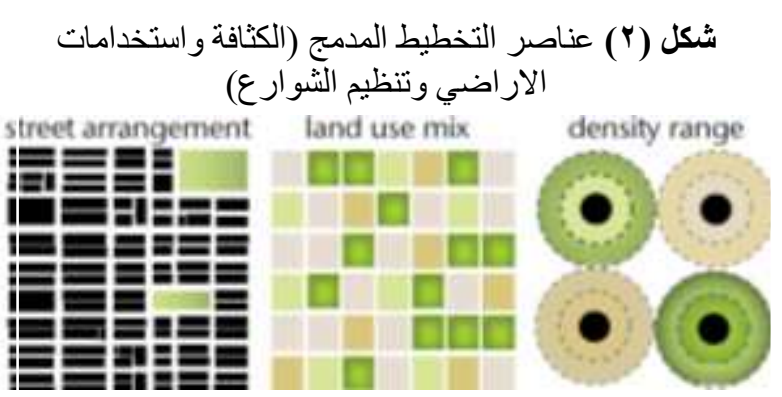

(Teed, Patric Condon, 2005)

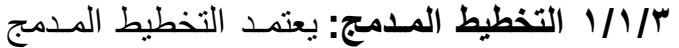

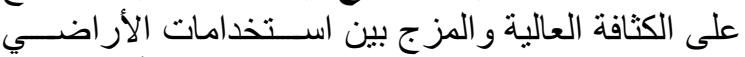

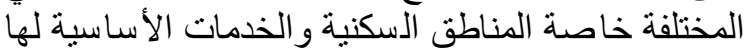

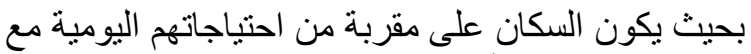

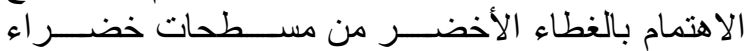

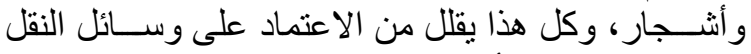

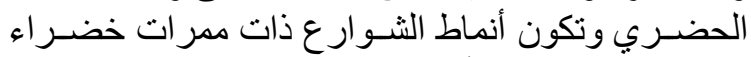

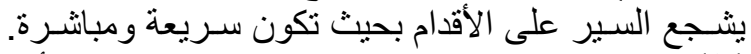

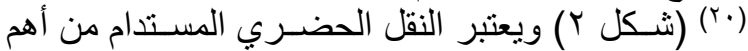

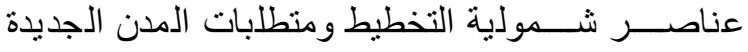

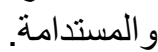

ب/

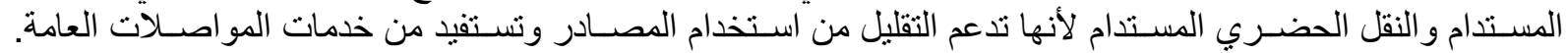

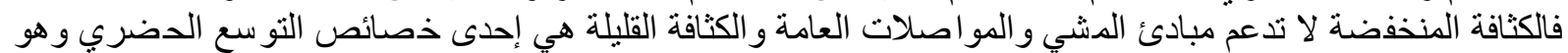

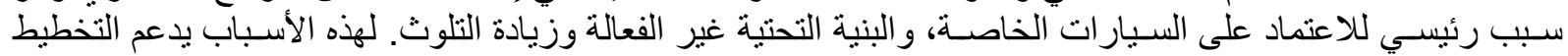

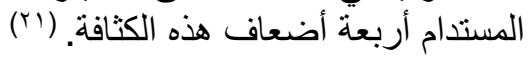

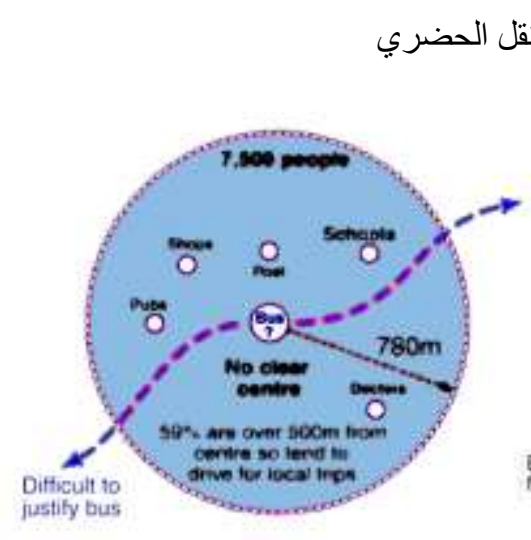

Population to support good neighbourhood facilities

$$
\text { المكان يحتاجون ألى وعيلة نقل }
$$

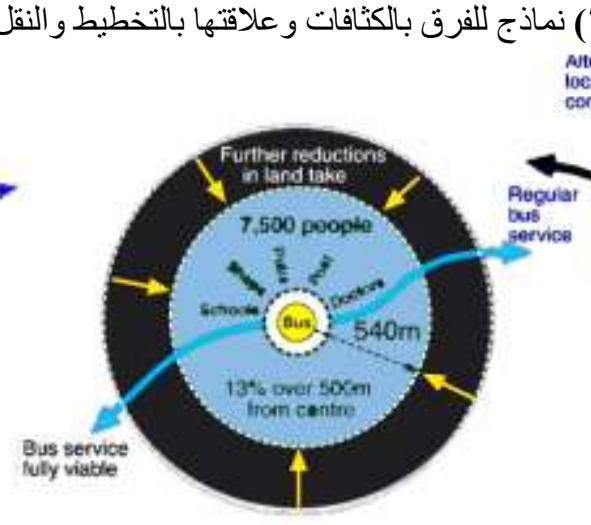

Everyone should be able to walk to their local centre

$$
\begin{aligned}
& \text { العنكان يسنطيعون المثنى إلى المركز } \\
& 10 \text { انفصص/هكثاز }
\end{aligned}
$$

(Y) (CLIFF MOUGHTIN, 2003)

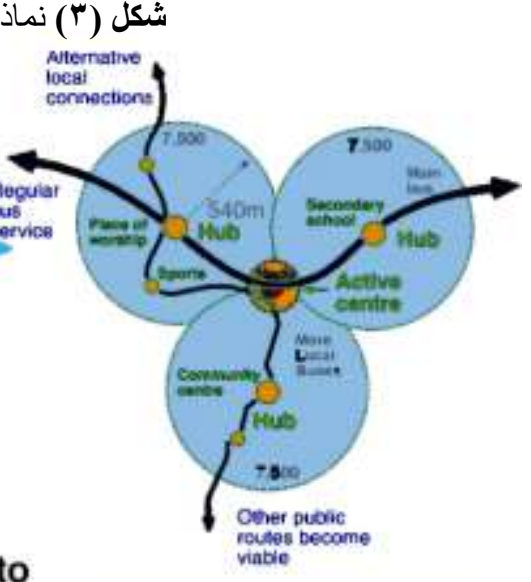

Neighbourhoods, districts and public transport

$$
\text { نقل علم نسوئهي اللمجلورة: الدي }
$$


شكل ( ) الكثافات و علافتها بالتخطيط او النقل

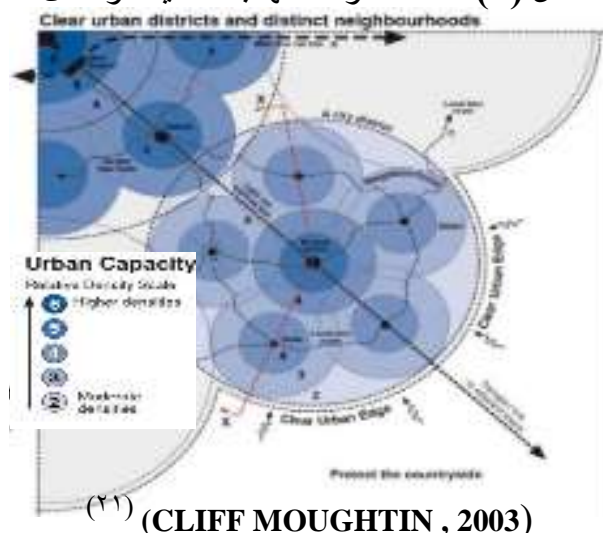

استــتهلاك الطاقة للمدن الكبرى في العالم، وقد

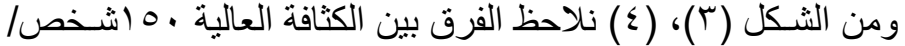

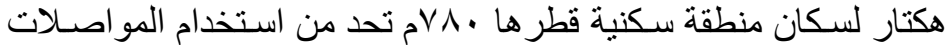

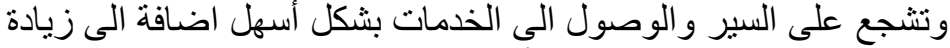

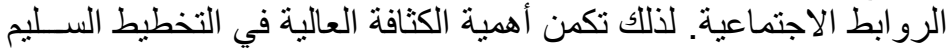

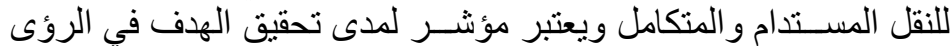

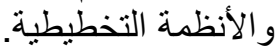

وتعظم زيادة الكثافة فعالية أنظمة المو اصـــلات العامة وخدماتهاتها.

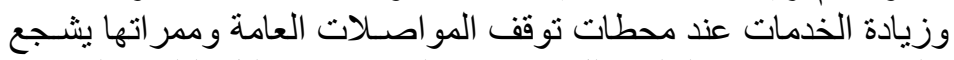

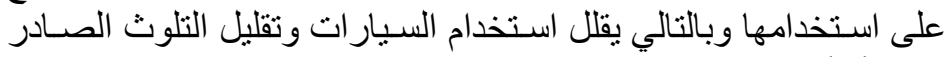
منها. (r)

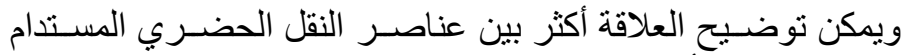

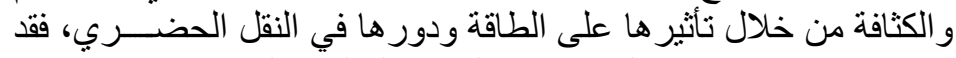

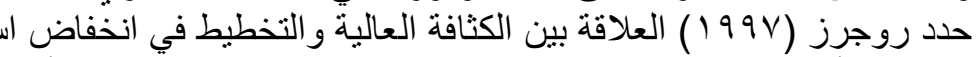

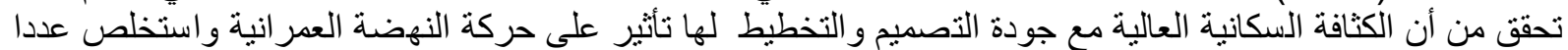

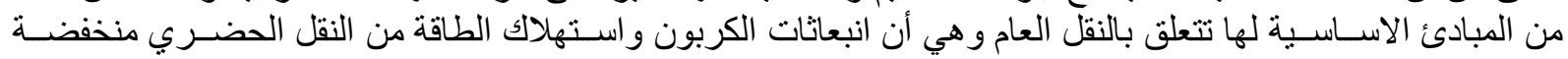

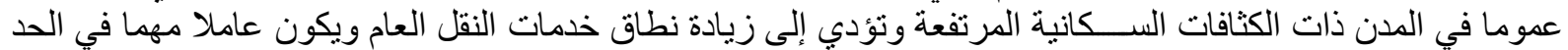

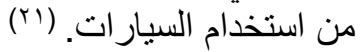

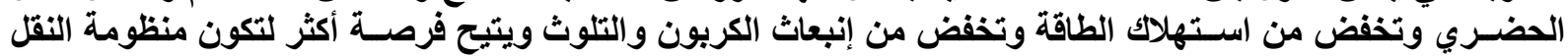

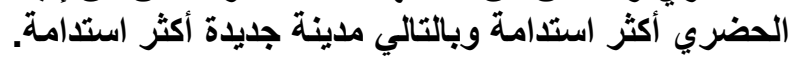

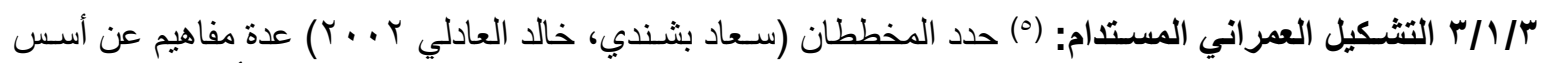

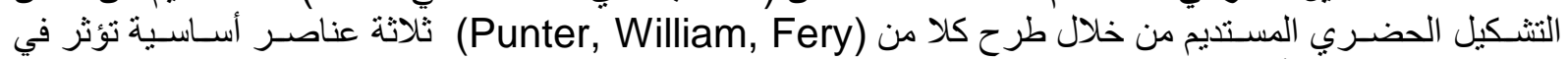

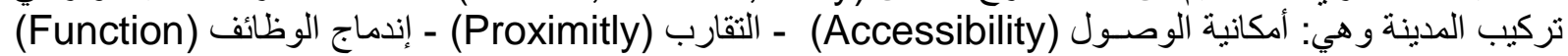

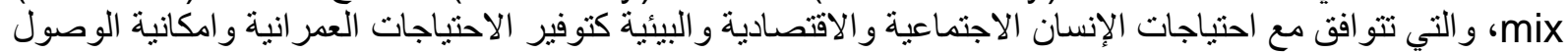

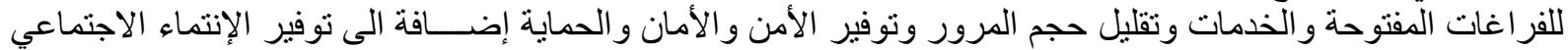

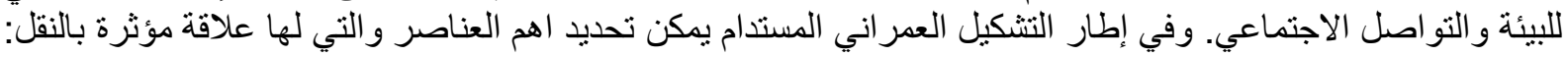
توجيه المدينة: حيث يؤثر نوجيه المدينة واحتر ام الاشعاع الثمسي خاصة في المناطق ذات المات الميول في درجة الحر ارة

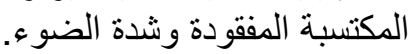

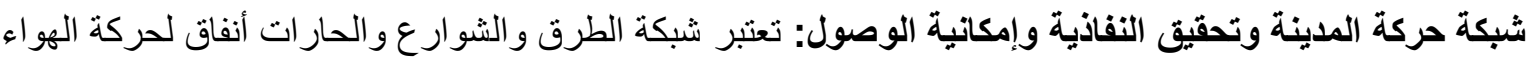

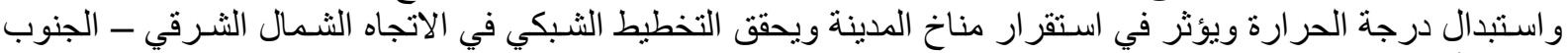

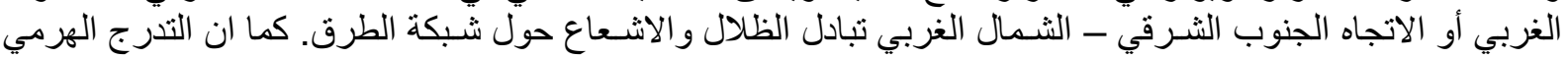

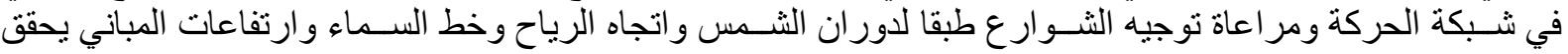

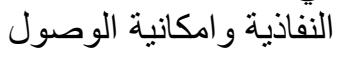

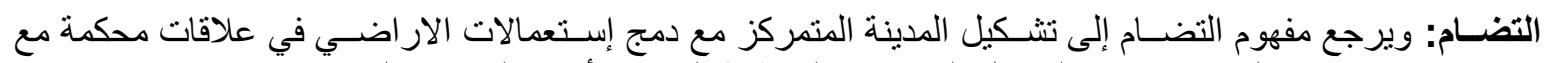

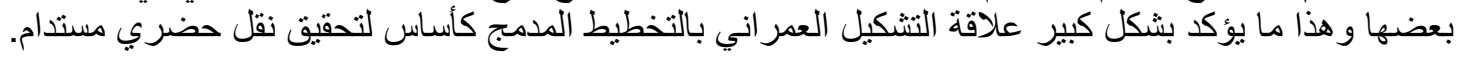

ع النقل الحضري المستدام

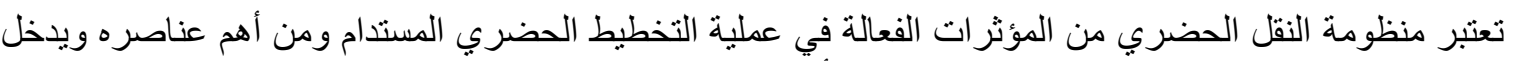

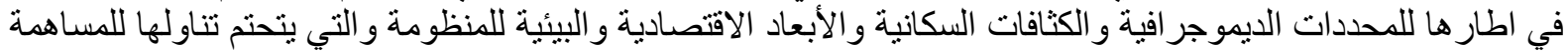

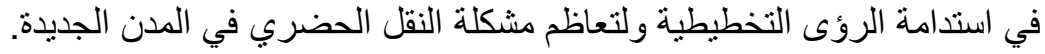

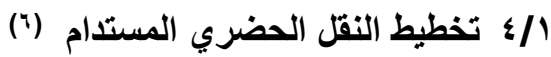

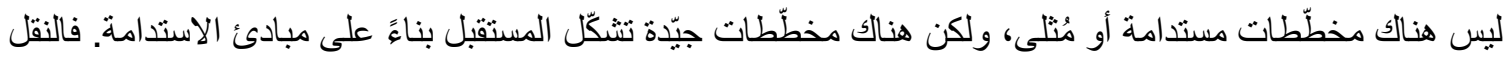

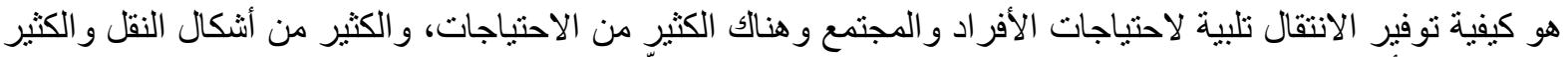

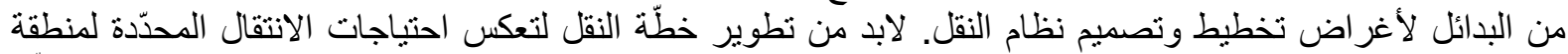

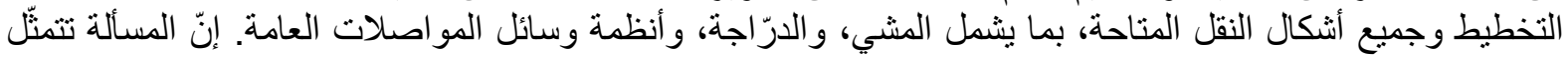


في كيفية تخطيط وتصميم تلك الأنظمة والعناصر الفردية كي تلبّي الاحتياجات البشرية بأسلوب كفه وفمّالة التكلفة، و ألمساهمة في تحقيق الاستدامة. تخطئ.

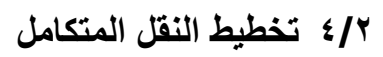

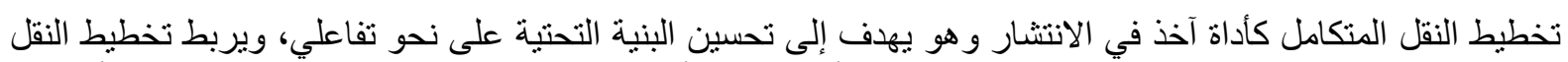

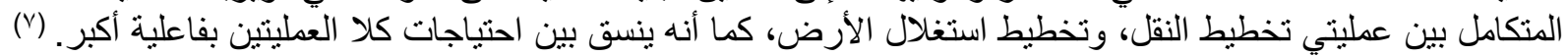

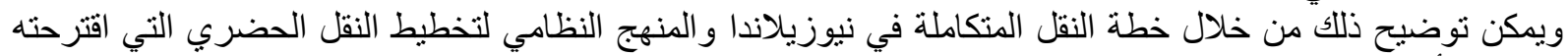
الوكالة الألمانية للتعاون الدولي (GIZ)

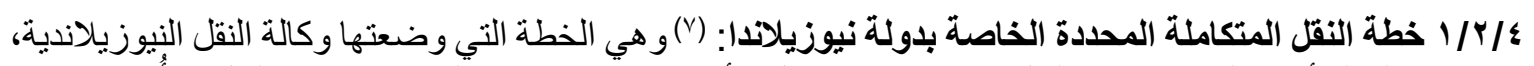

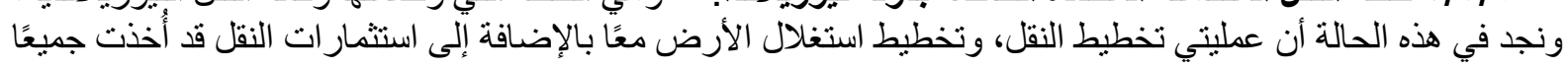
في الاعتبار.

تخطيط النقل: تشمل عملية التخطيط المرتبطة بتطوير وتثنيل أنشطة النقل البري متعددة الجو انب و ولان سيما البنية التحتية

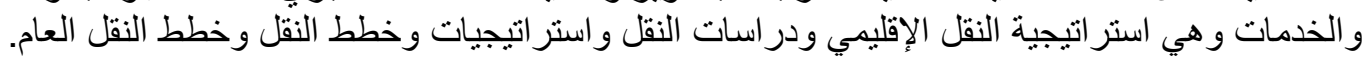

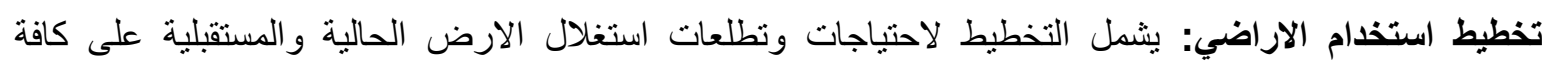

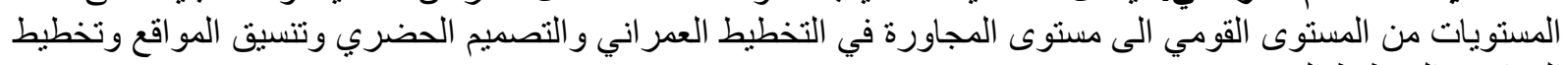
الموارد و التخطيط البيئي.

استثمارات النقل: تنثمل الاستثمار ات في انشطة النقل البري من كافة المؤسسات و الجهات الحكومية والخاصة.

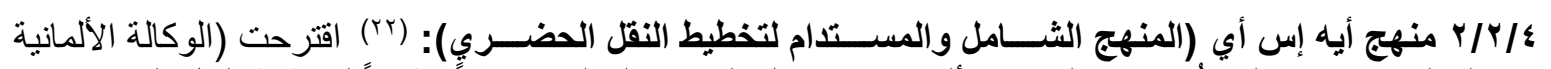

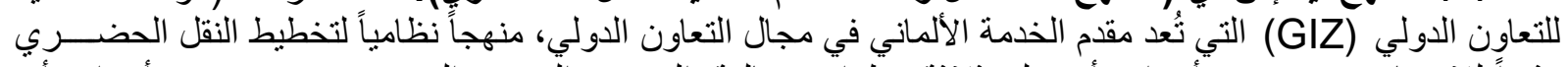

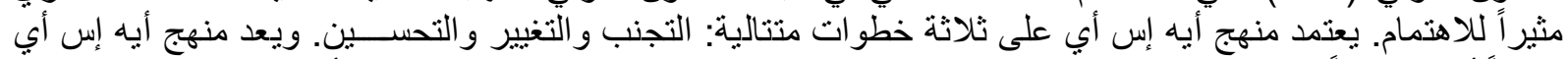

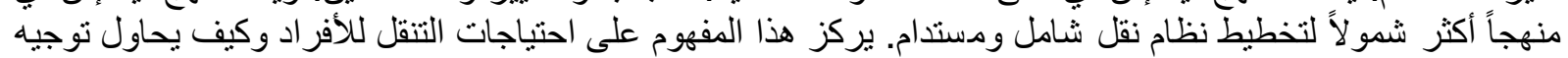

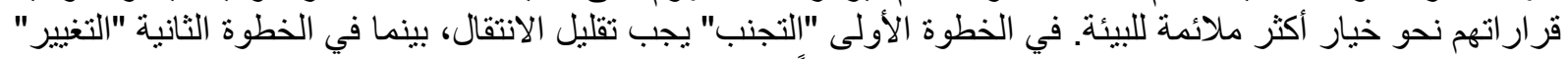

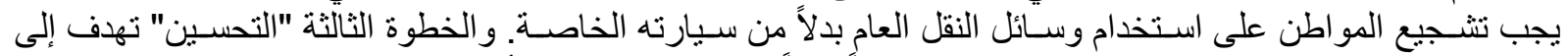
التقليل من حجم السيارة وتقديم بنية تحتية مجزة تجهيزاً جيداً في المدن. الوكالة الألمانية للتعاون الدولي. (GIZ)

$$
\text { شكل (•) منهج أيه إس أي (الوكالة الألمانبة للتعاون الدولي) }
$$

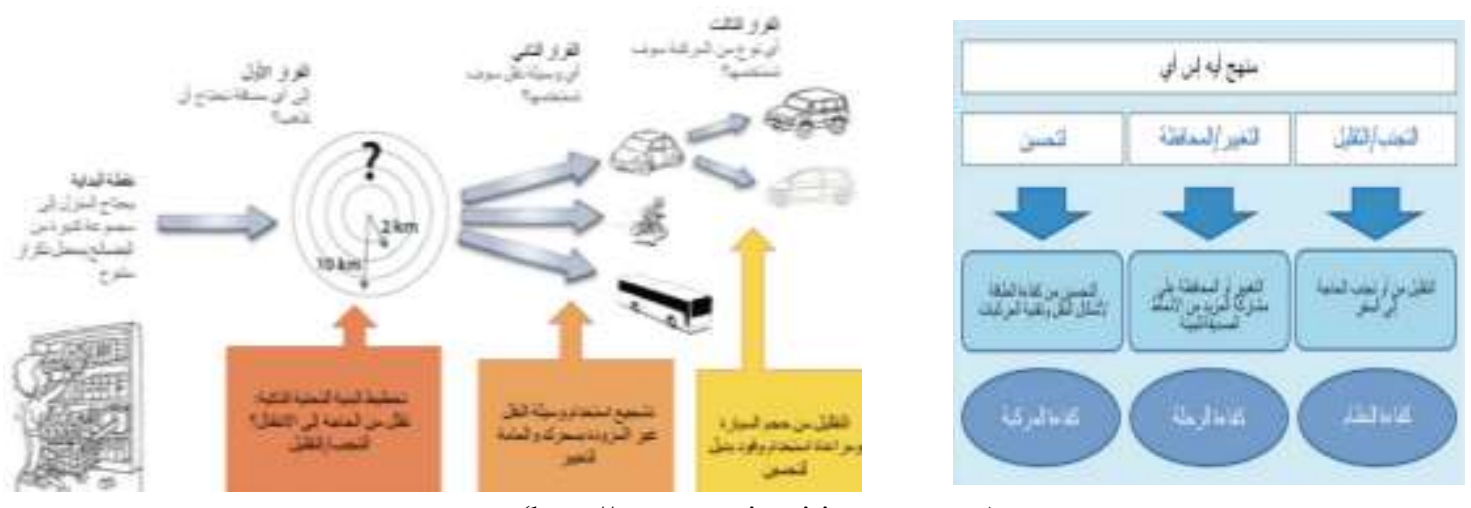

(http://www.envirocitiesmag.com)

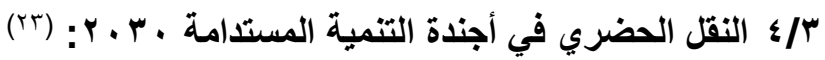

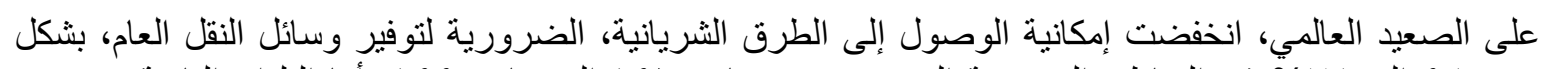

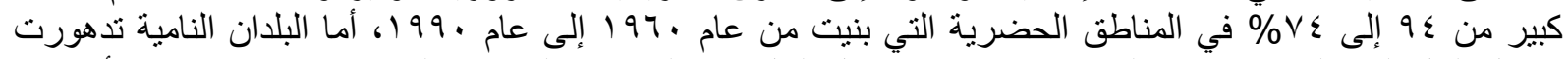

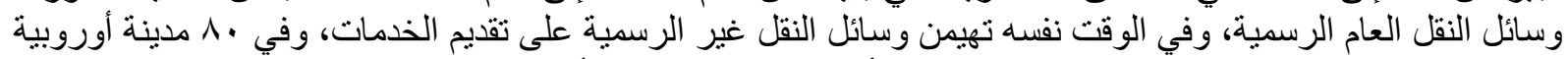

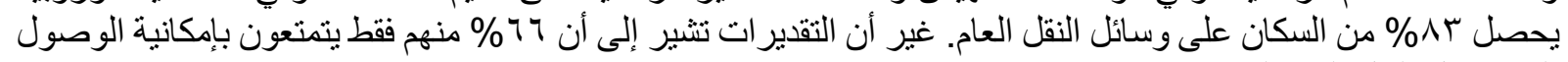
إلى وسائل النقل العام الملائمة. 


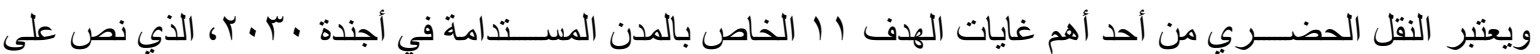

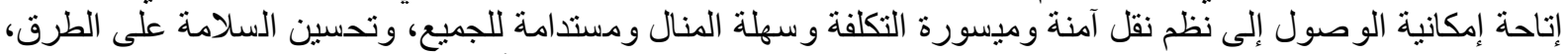

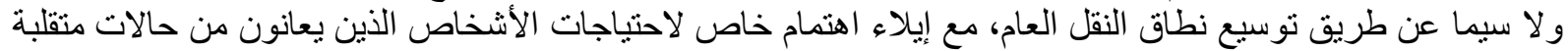

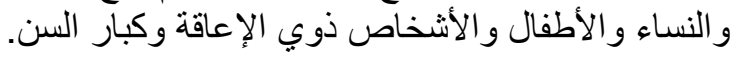

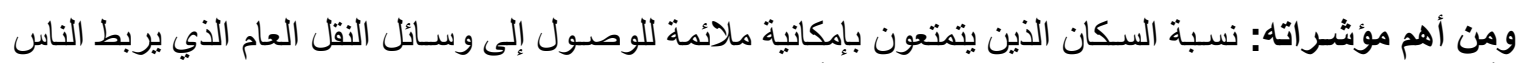

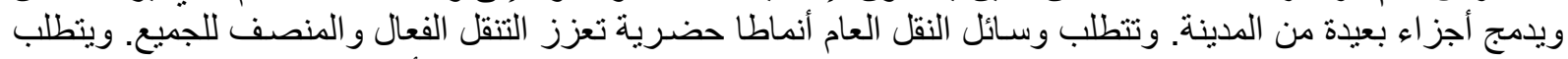

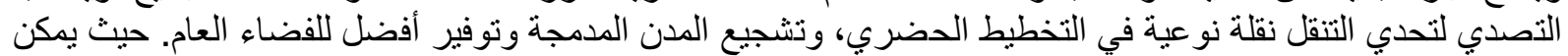

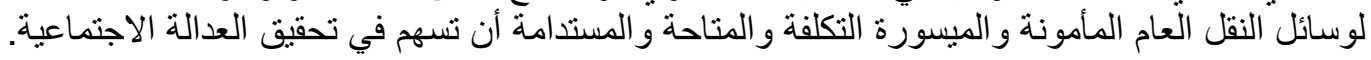

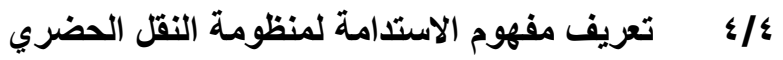

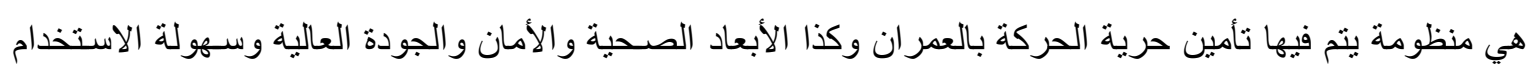

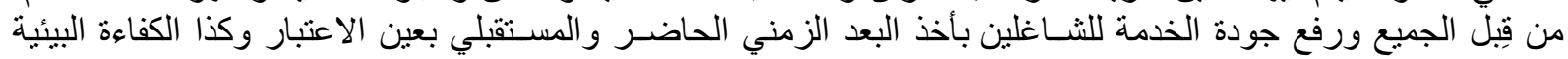

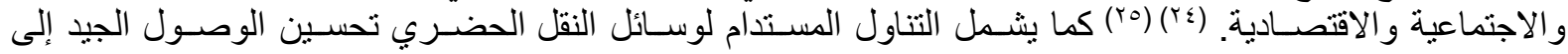

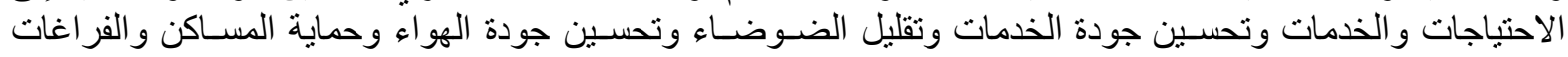

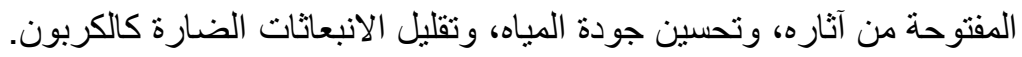

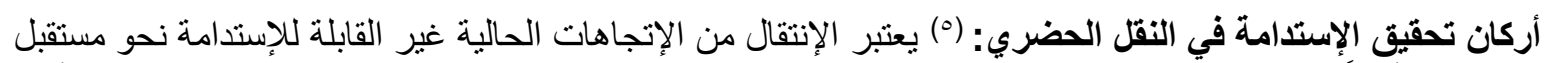

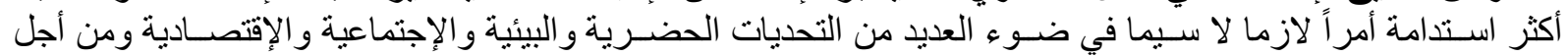

تحقيق تلك الأهداف يتطلب الامر التعرف على معايير ومقاييس اداء منظومة النقل في المناطئ الإنق الحضرية ومن أهمها:

(المكانبة الوصول (Accessibility) ( / الصحة و الأمان (Health and Safety)

r/ التكلفة (Cost Effectiveness)

$$
\text { ع / استهلاك الموارد الطبيعية }
$$

/ / التأثير ات البيئية المحتملة (Production of plutants).

و هذه المعايير تستخدم لقياس الاستدامة في جو انبها المختلفة الاجتماعية والاقتصادية و البيئية.

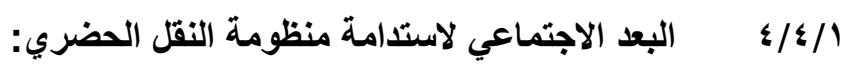

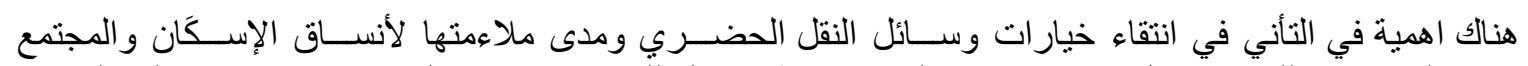

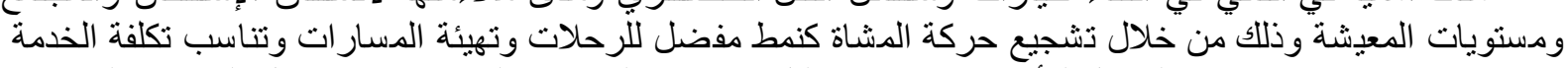

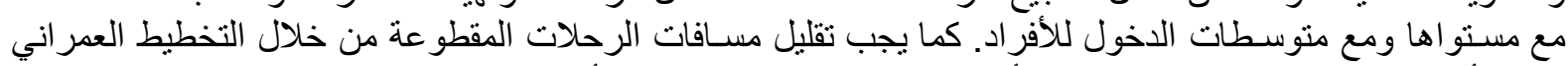

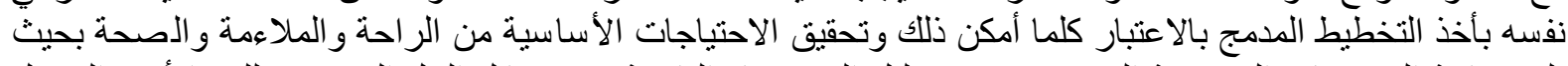

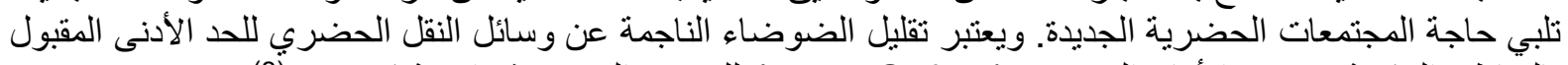

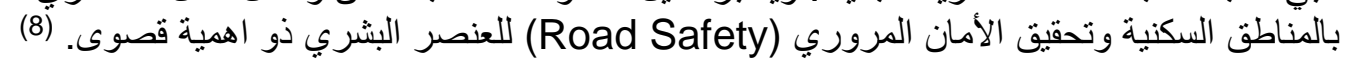

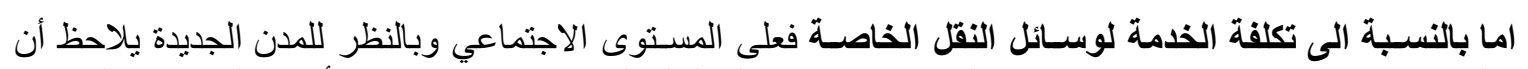

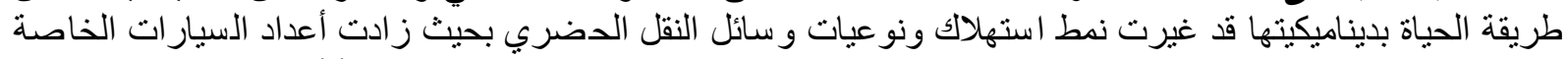

كما غيرت نسف استعمالها بحيث صار الاعتماد عليرت عليها بشكل كبير وحتى في الرحلات القصيرة.

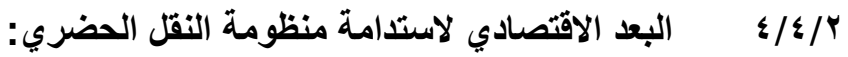

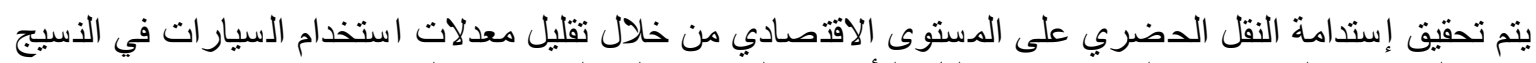

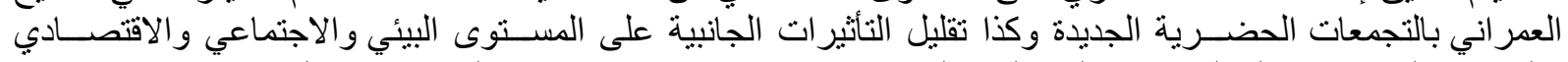

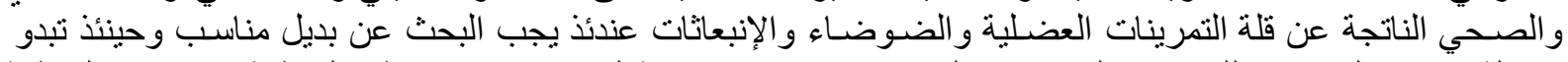

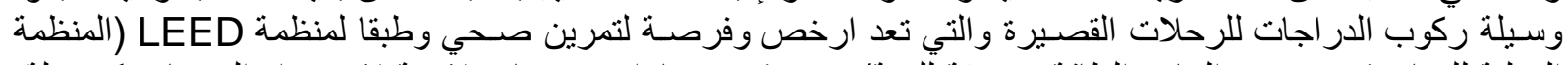

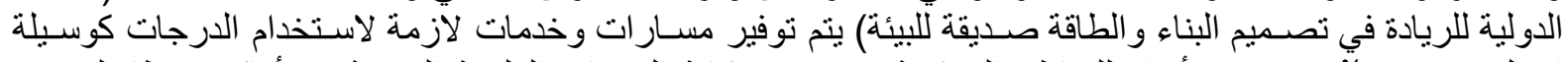

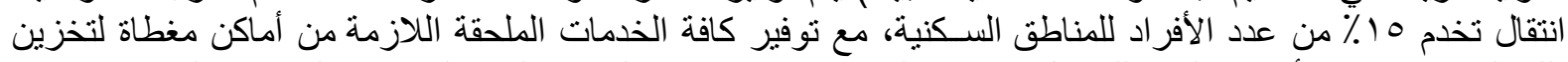

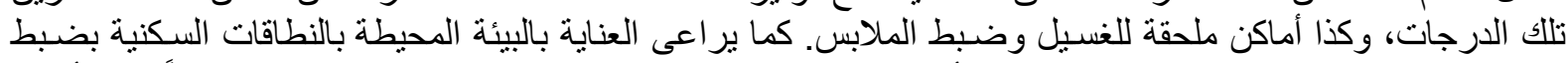

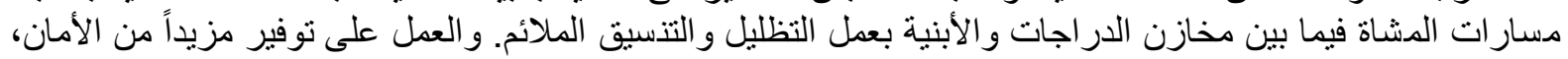




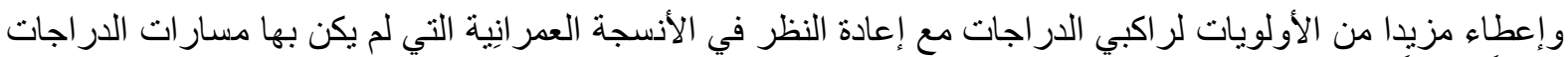

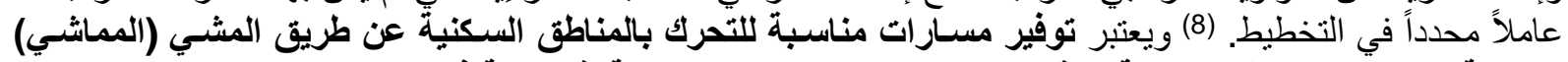
ودراسة بائل مركبات غير تقليدية الوقود اهم الإجراءات لتحقير التيق استدامة اقتصادية في النقل الحضري.

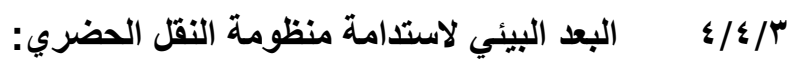

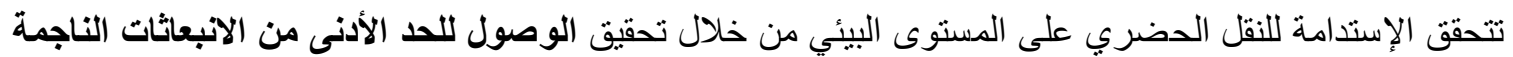

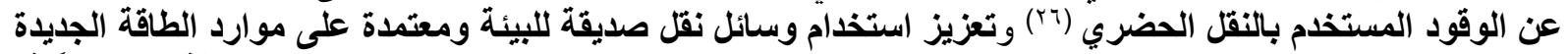

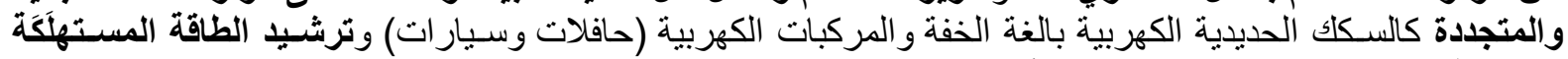

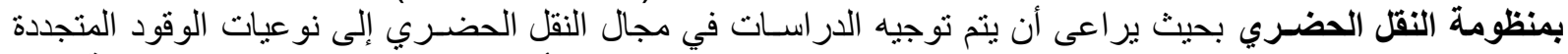

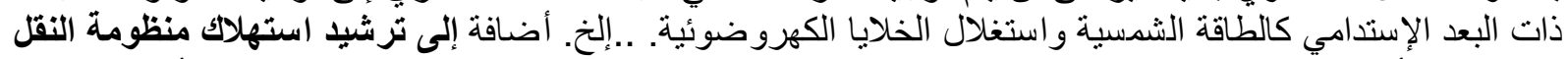

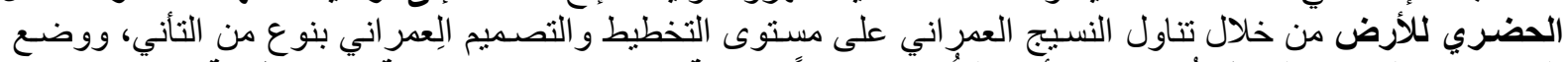

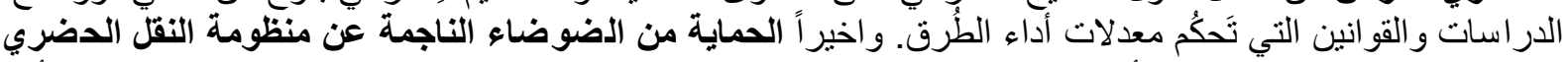

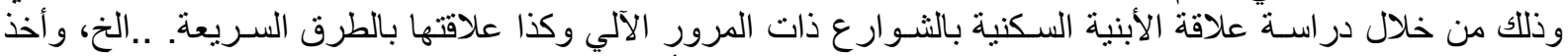

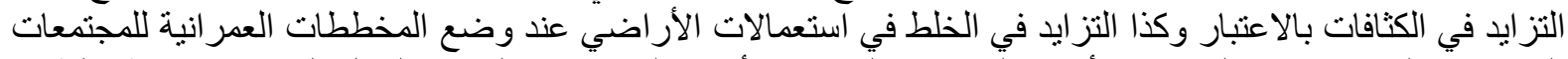

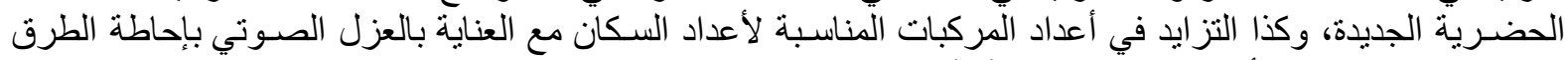

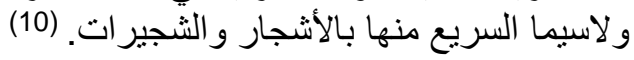

ه التجارب العربية والعالمية للمدن المستدامة

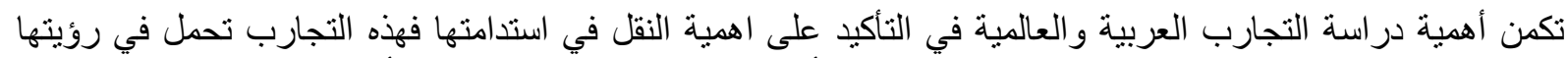

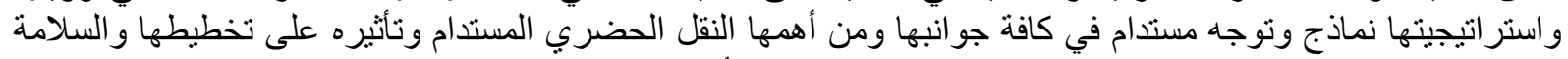

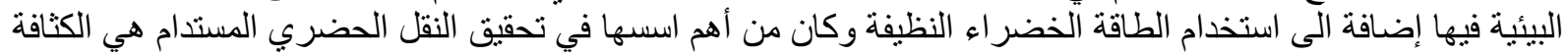

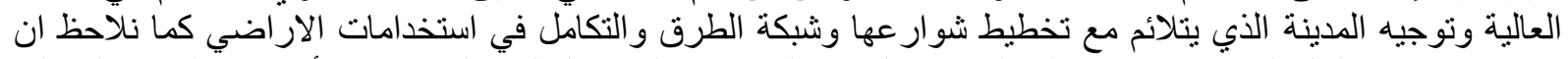

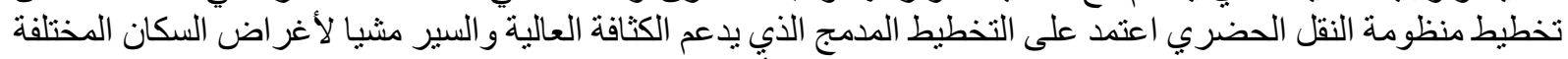

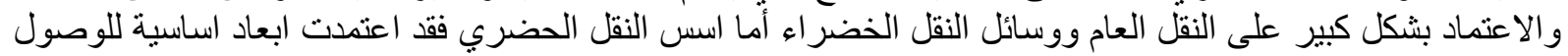

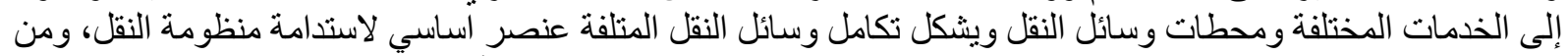

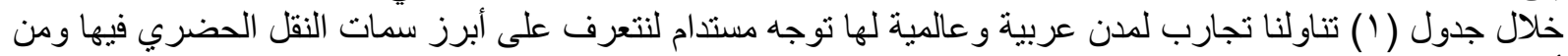

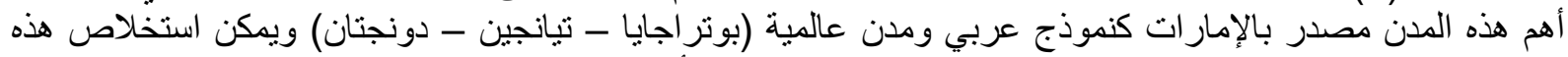

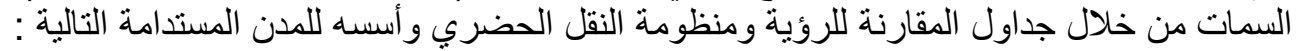

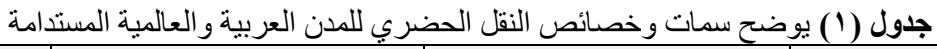

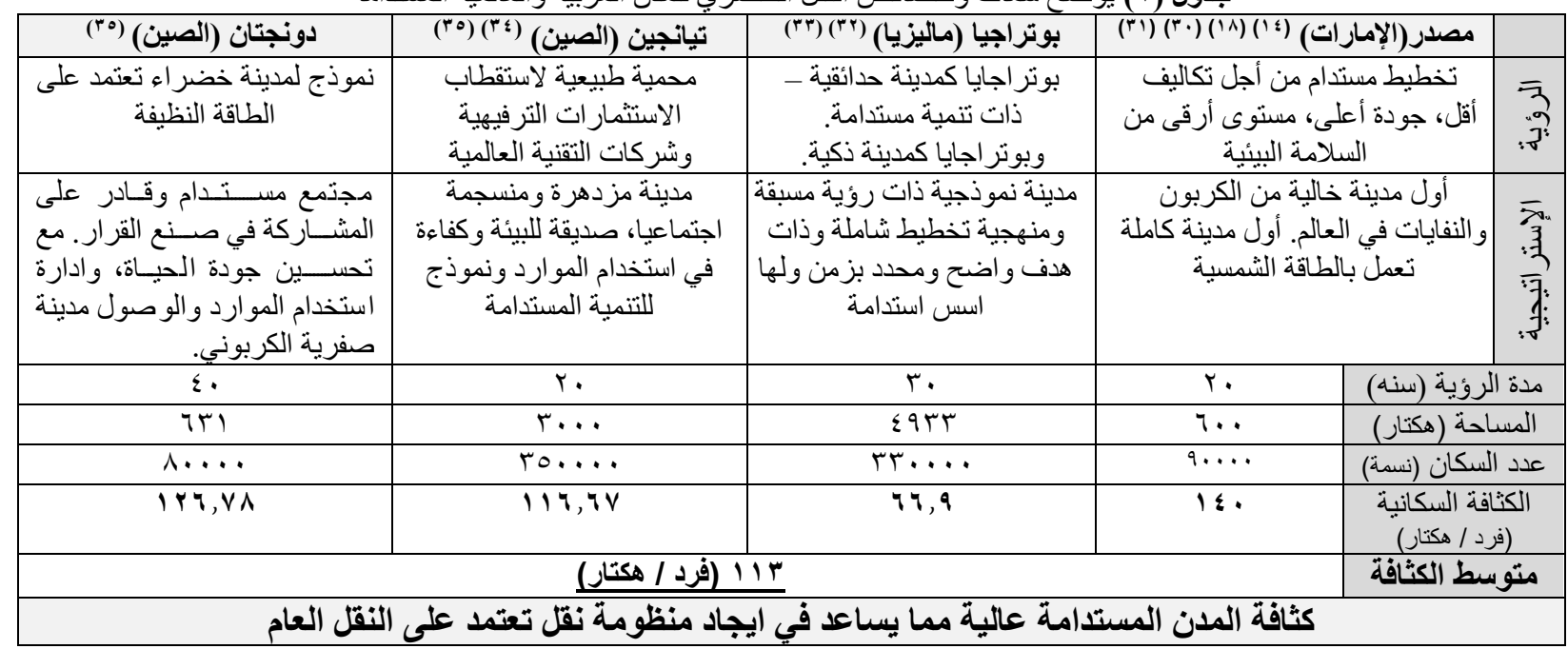




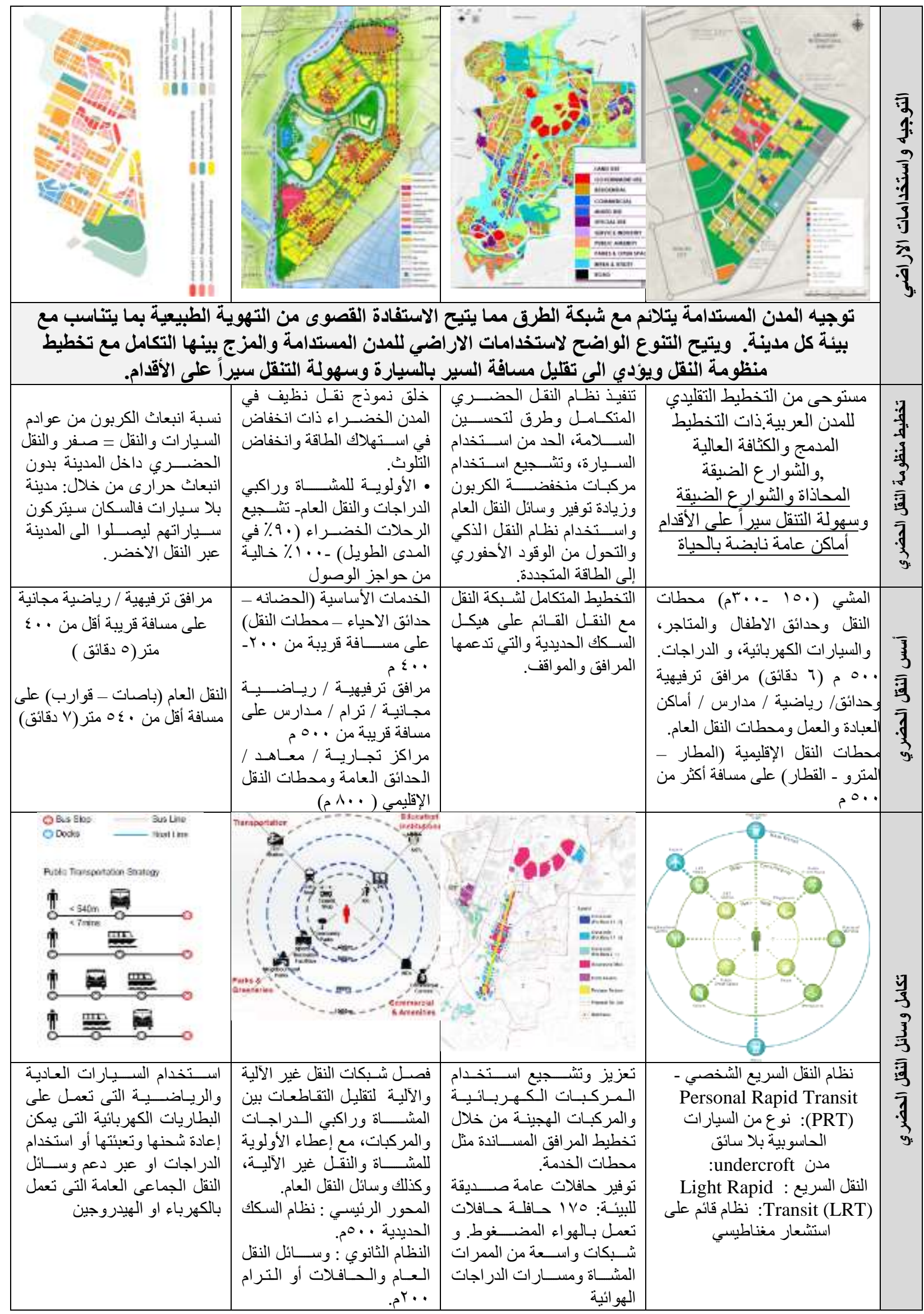




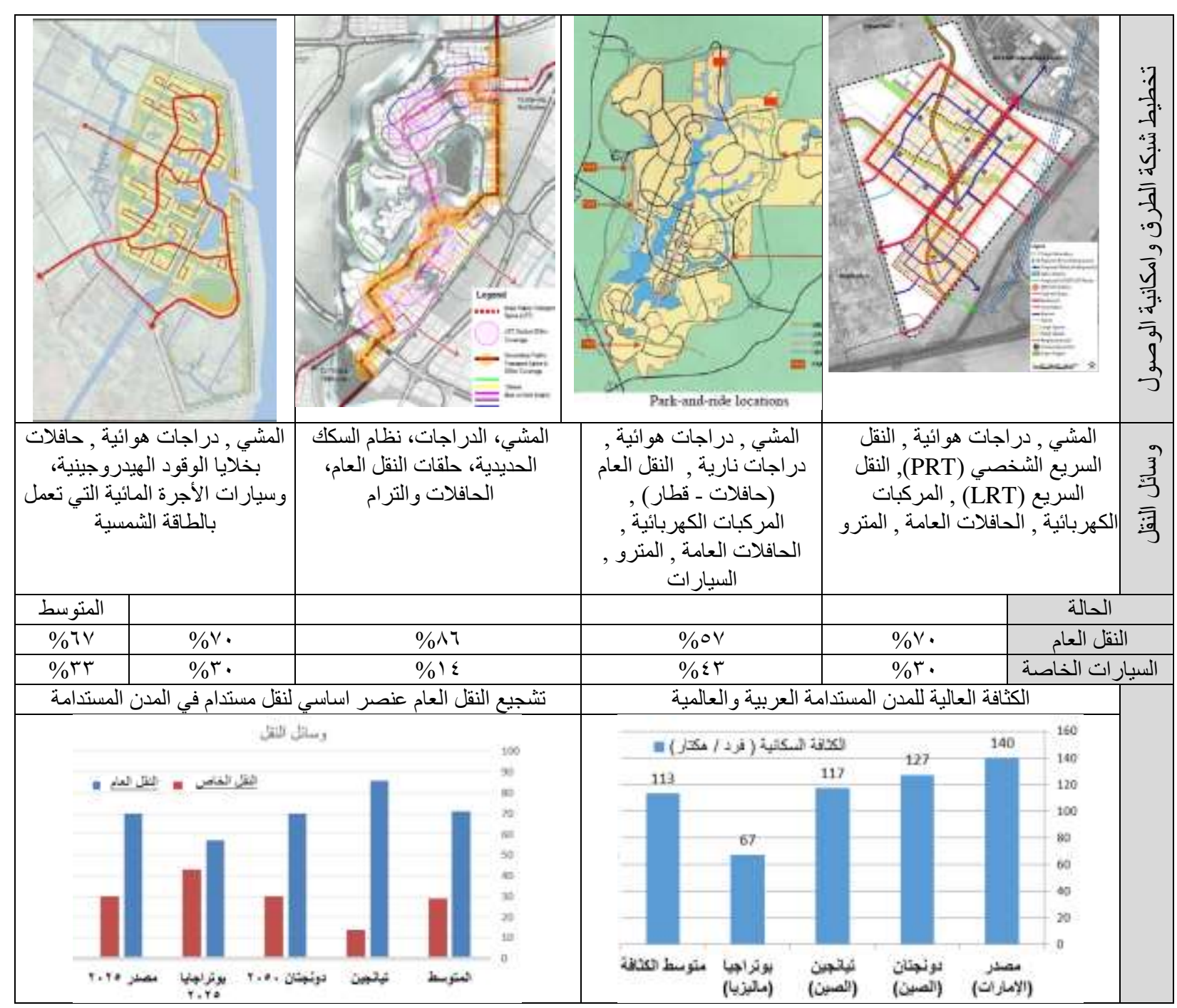

من خلال ما سبق نستنتج ان أهم ما اتسمت به المدن المستدامة لرؤى و استر اتيجيات ذات بعد استدامي في كافة جو انبها

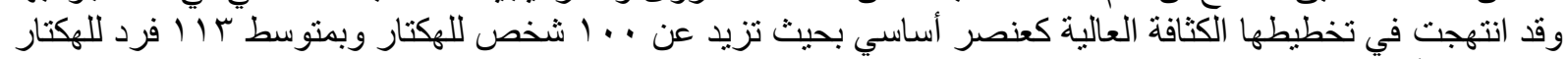
و هذا يؤكد أهميتها في دعم منظومة نقل مستدام.

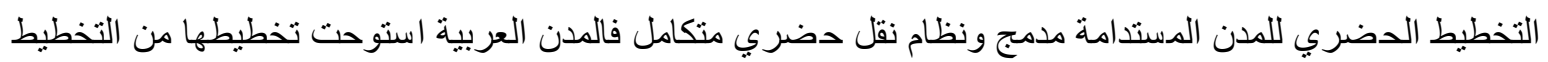

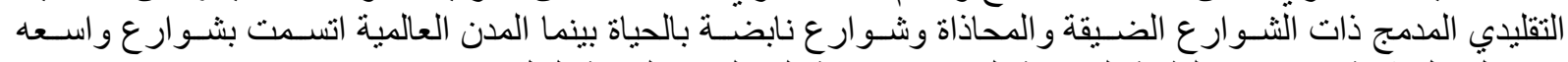

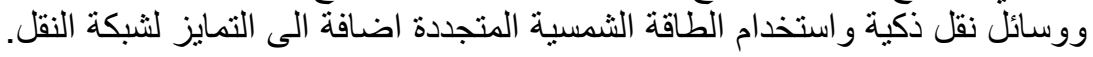

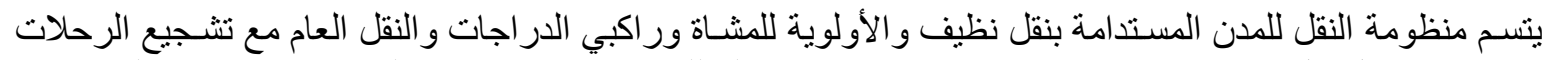

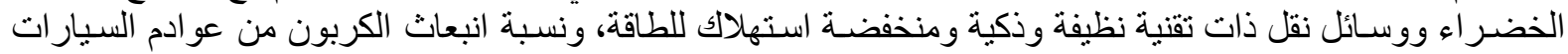
و النقل منخفضة جداء وبعد الخدمات عن وسائل النقل مناسب جنات

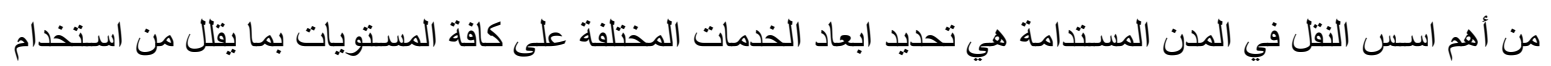

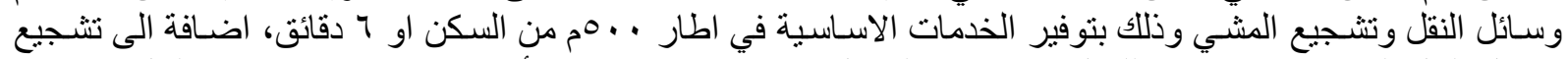

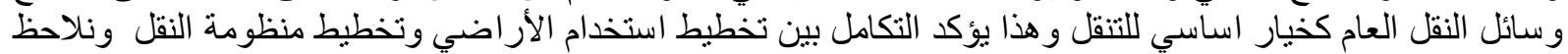

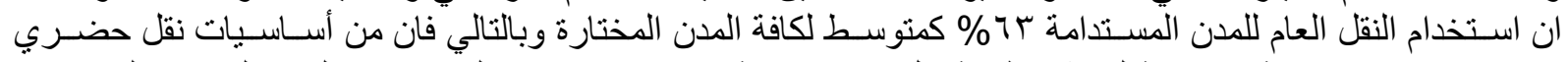
مسـتدام هو اسـتر اتيجية واضـــة لتنفيذ منظومة نقل عام مع كافة خدماتها وتثـجيع السـكان في المدن الجديدة على اختبار 


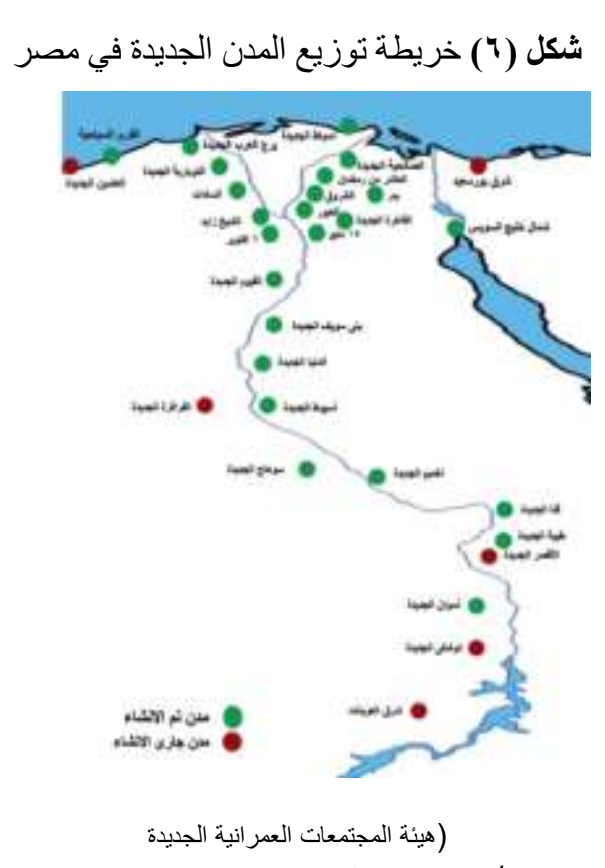

www.newcities.gov.eg/know_cities/

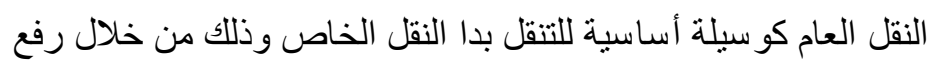

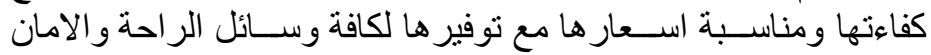

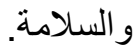

7

جاء اختيار المدن المصرية الجديدة في هذه الدراسة نظرا لانها

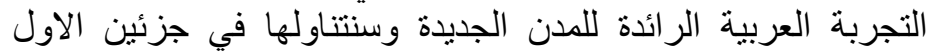

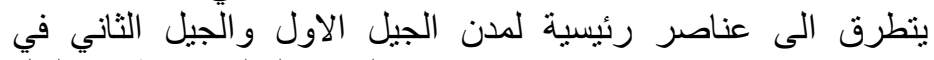

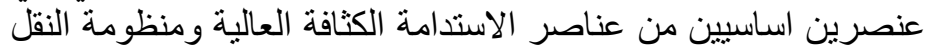

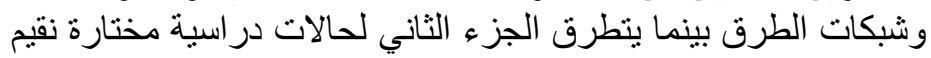

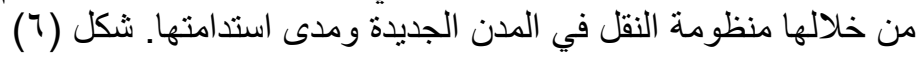

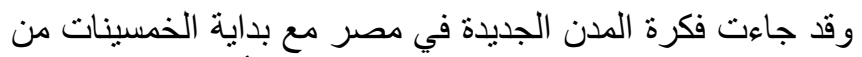

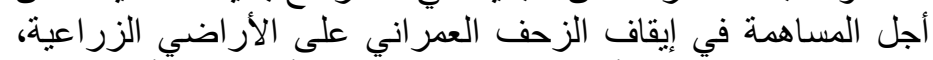

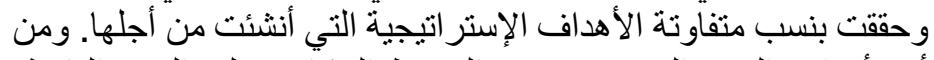

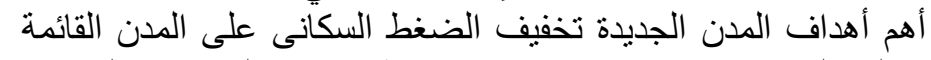

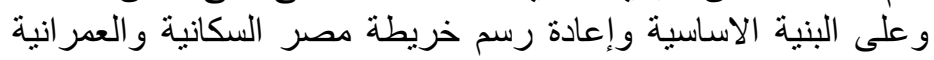

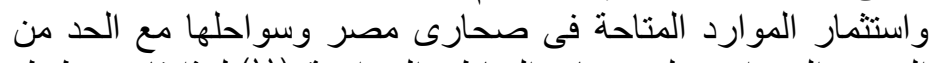

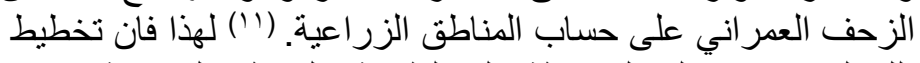

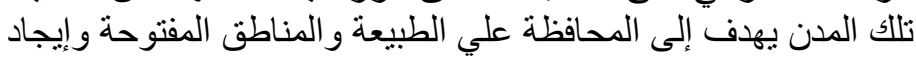

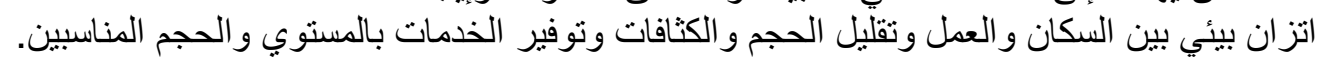

\section{(1/ الكثافة السكانية}

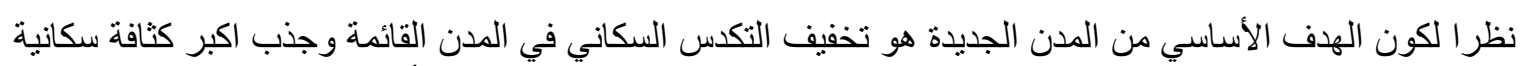

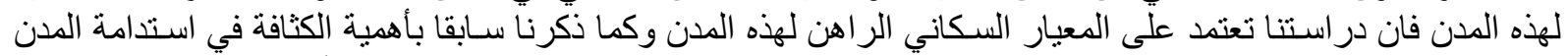

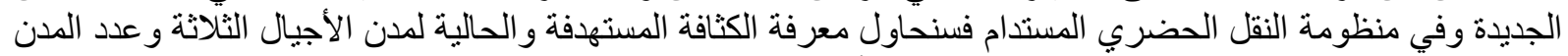

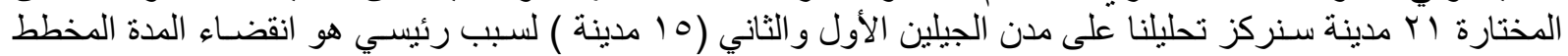

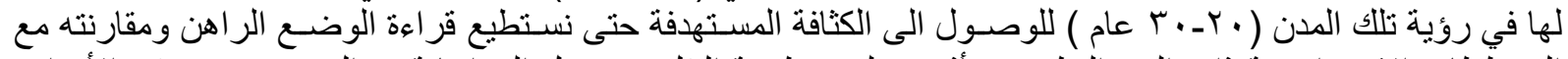

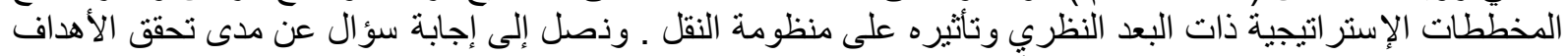

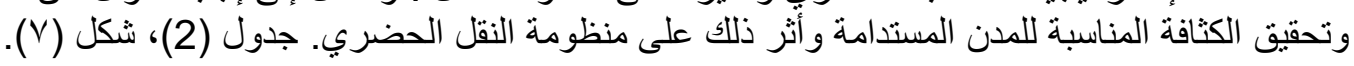

\begin{tabular}{|c|c|c|c|c|c|c|c|}
\hline النسبة بين الكثافة الراهنة & 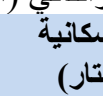 & (الكثافة & (بالألف) & عد السكار & المساحة & 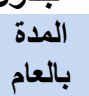 & المدينة \\
\hline$\%$ & الر اهن & المستهدف & الر اهن & المستهدف & بالهكتار & & \\
\hline$\% Y_{0,7}$ & Tr, & IYT,Y & rVq. & 1.94. & N70.r & ro & الجيل الأول \\
\hline$\% \mathbf{q}^{r}, r$ & $|7, \pi|$ & $\lambda \cdot, V_{4}$ & 1040 & V7. & $q \leqslant 1 Y T$ & ro & الجيل الثاني \\
\hline$\overline{\% r r, \varepsilon}$ & $r \varepsilon$ & $1 \cdot r, 7$ & ETro & 110r| & 11.740 & $r$. & المتوسط \\
\hline
\end{tabular}

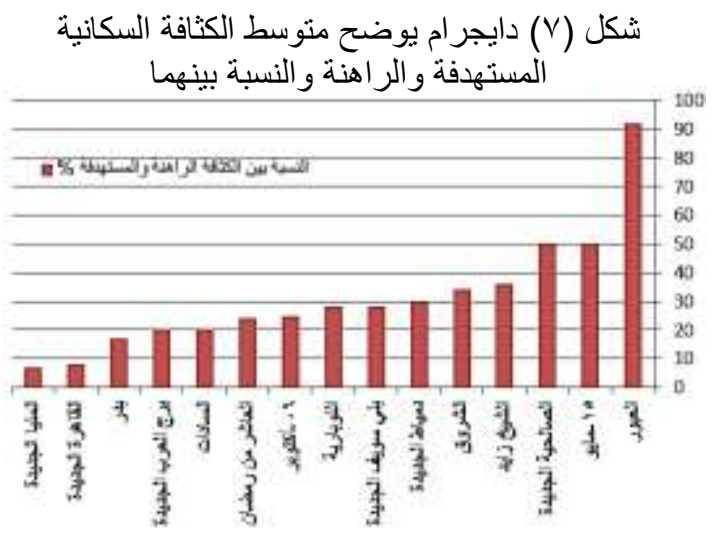

المصدر: (الباحث)

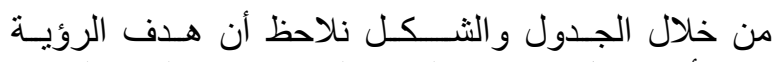

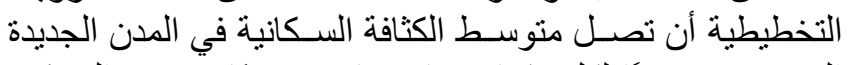

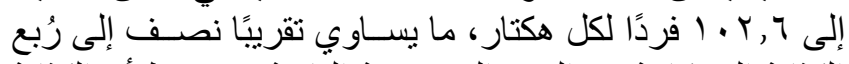

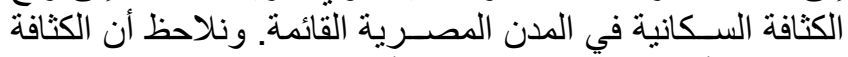

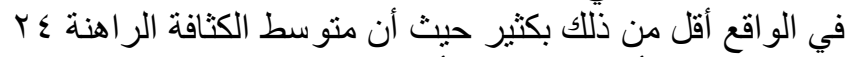

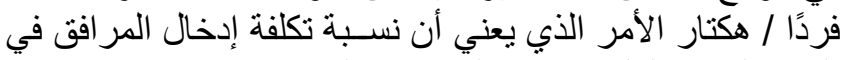

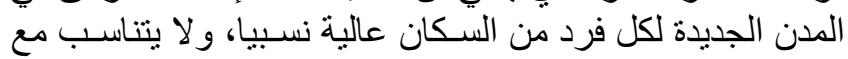

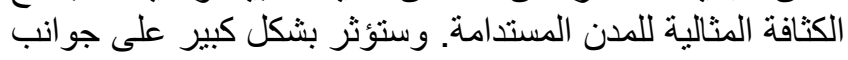

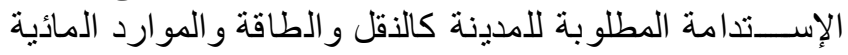

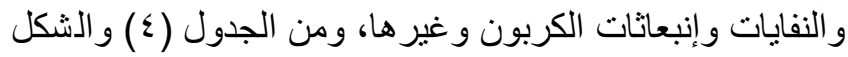

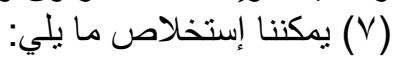




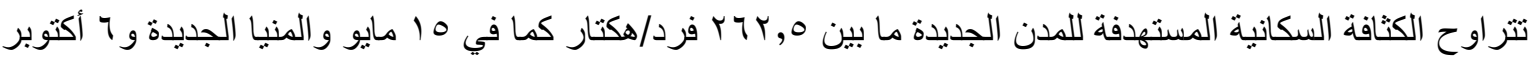

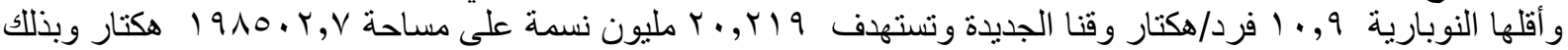

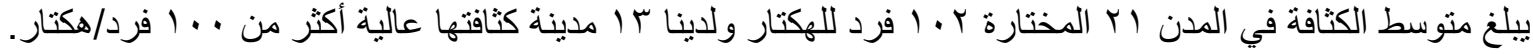

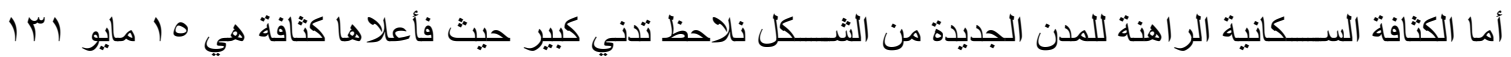

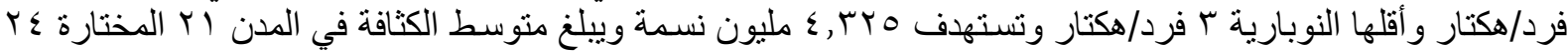
فرد للهكتار.

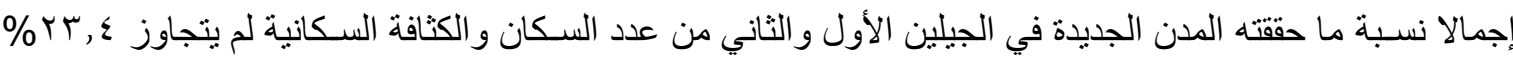
من المستهدف فهي لم تصل إلى الربع.

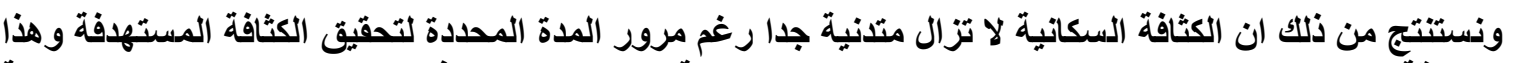

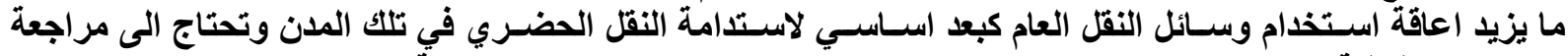

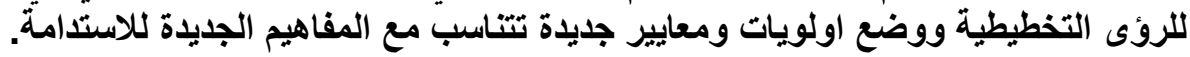

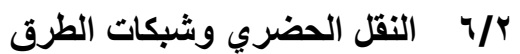

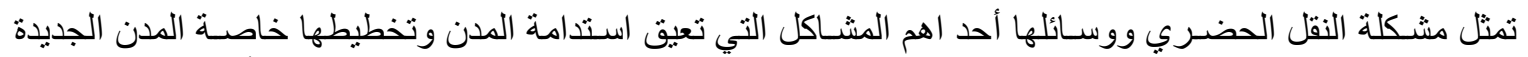

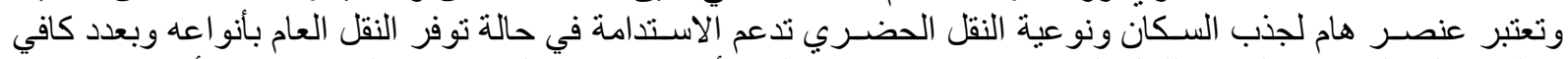

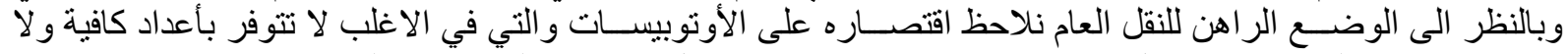

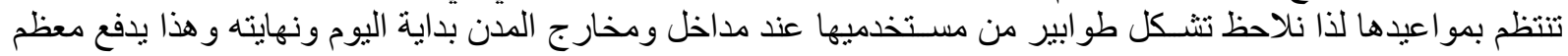

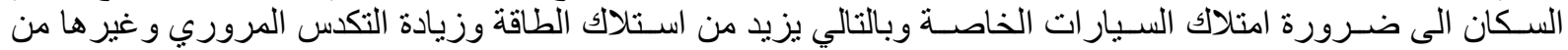

المشاكل المعيقة للاستدامة.

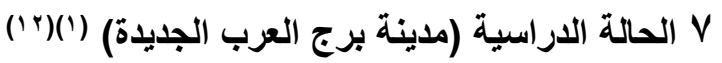

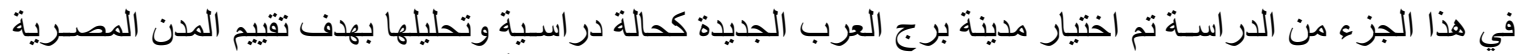

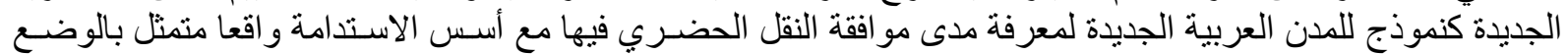

شكل (^) موقع مدينة برج العرب (جهاز المدينة)

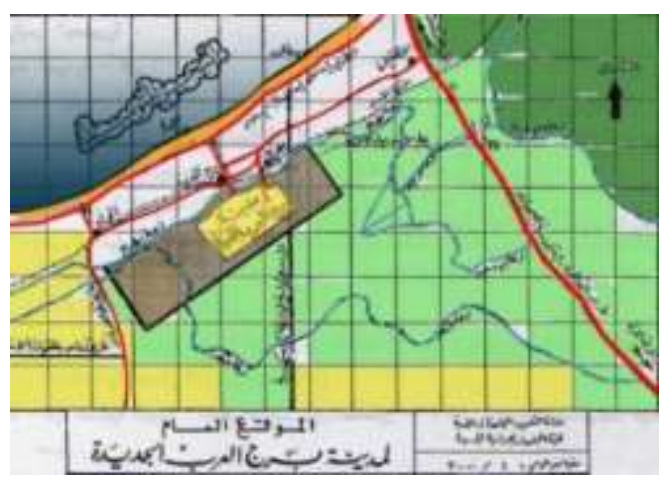

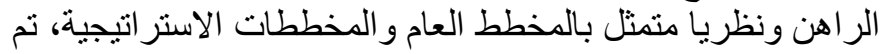

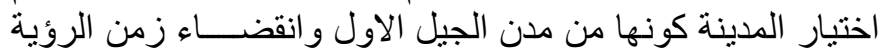

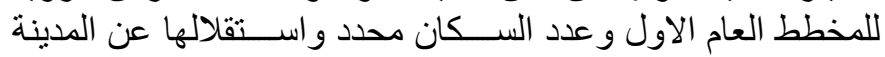
القديمة ولهما قاعده اقتصادية وتم و وضع مخطط استر اتيجي حديث.

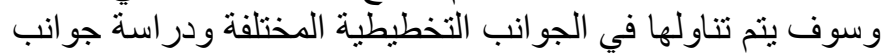

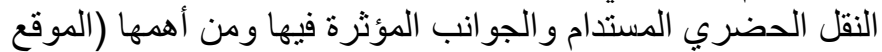

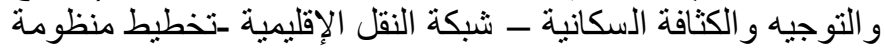

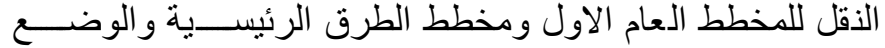
الر الهن لها.

V/l

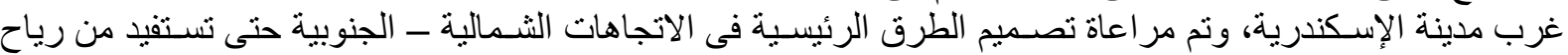

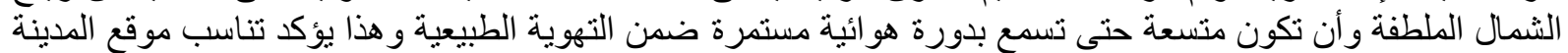

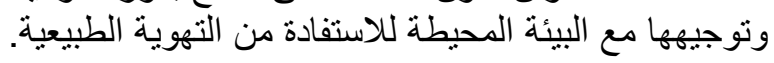
V/r

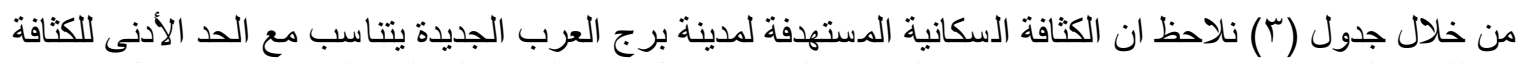

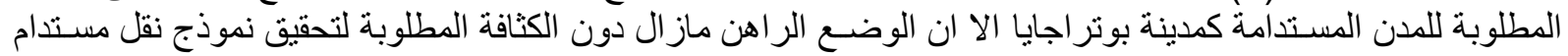

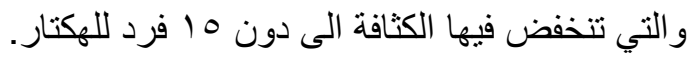

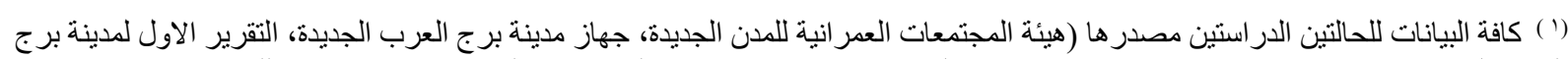

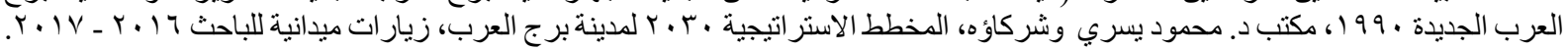




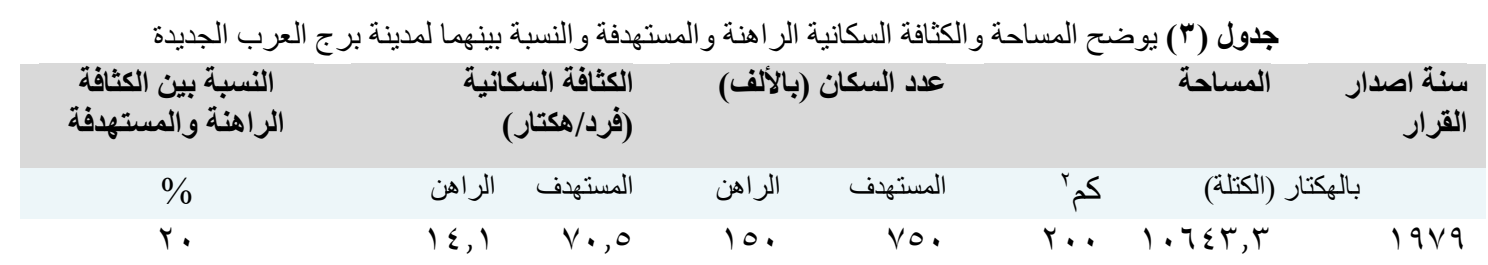

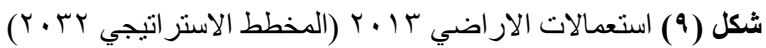

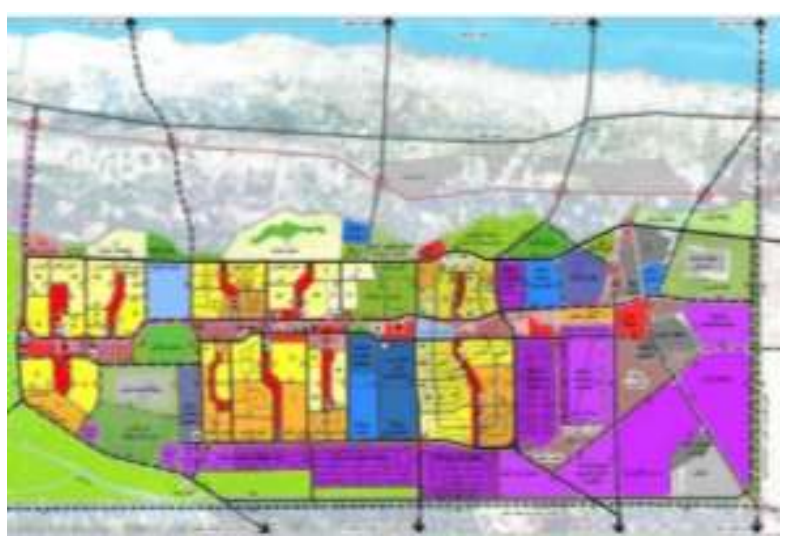

V/ استخدام الاراضي للمخطط العام وامكانية الوصول: - (الورن

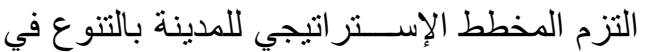

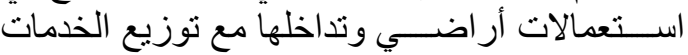

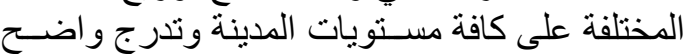

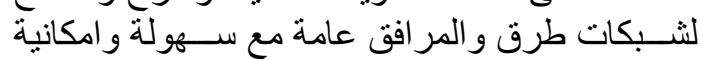

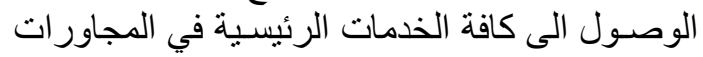

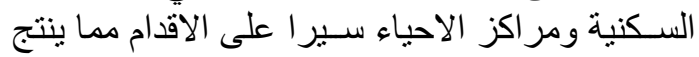

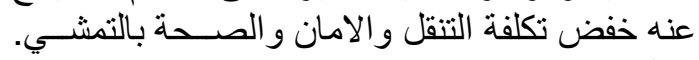

(9) شنكل

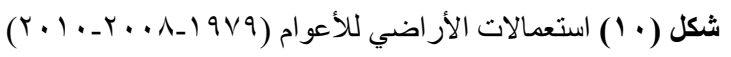

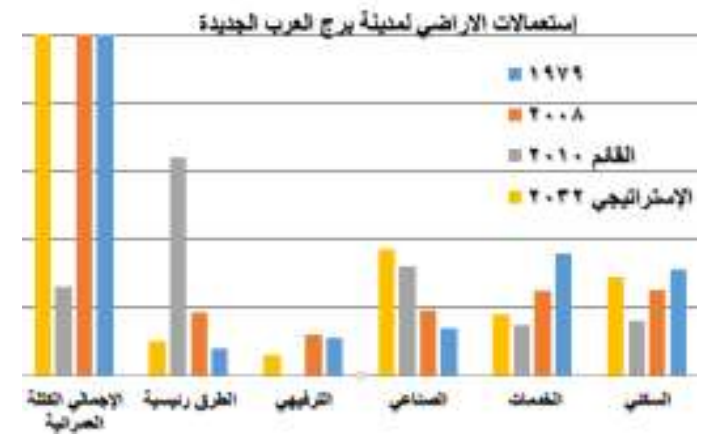

\begin{tabular}{|c|c|c|c|c|}
\hline \multicolumn{5}{|c|}{ 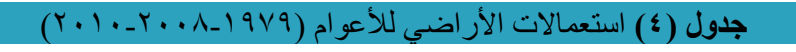 } \\
\hline الإستراتيجي & 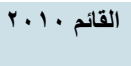 & r... & $19 \vee 9$ & المخطط العام \\
\hline$\%$ & $\%$ & $\%$ & $\%$ & استعمالات الأراضي / المساحة \\
\hline$r \Lambda, \Lambda$ & $r .17$ & ro,r & r & السكنى \\
\hline $1 \Lambda, 1$ & $10, r$ & $r \leqslant, q$ & rч & الذذمي \\
\hline$r 4,9$ & rT & 19,1 & $1 \varepsilon$ & الصناعي \\
\hline 0,9 & - & $\mid r, 1$ & 11 & الترفيهي \\
\hline $1 \cdot, r$ & $T \varepsilon$ & 11,7 & $\wedge$ & الطرق رئيسية \\
\hline $1 \ldots$ & 9. Yo $^{\circ}$ & $1 \ldots$ & $1 \ldots$ & إجمالي الكتلة \\
\hline
\end{tabular}

من خلال التحليل السابق للوضع القائم و المخطط له لاستخدامات الار اضي نلاحظ ان الطرق الرئيسية للمدينة مناسبة مع متطلباتها وكذلك الخدمات المركزية مما يعزز من استدامة منظومة النقل الحضري والتخان التخطيط المستدام، و اجمالا فان نسبة التغيير و التنفيذ

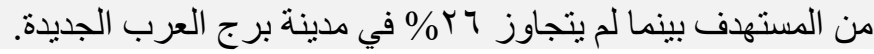

\section{V/\&}

وجود الطرق الإقليمية التي تحد المدينة مما يربطهما بالمدن المجاورة يؤكد على التخطيط الجيد للطرق ويســاهم في

منظومة نقل أكثر استدامة. شكل (1)

\section{V/P}

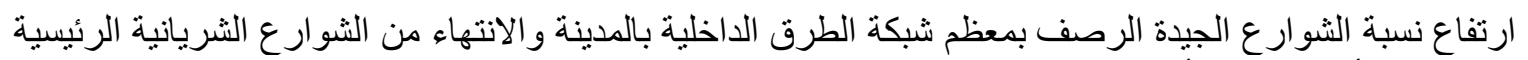

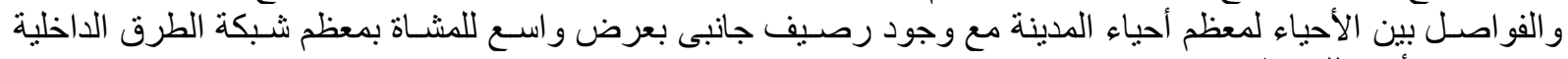
مما يحقق الأمان للمواطنين.

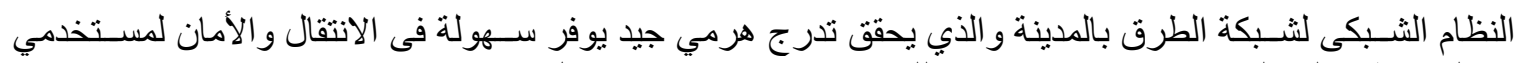

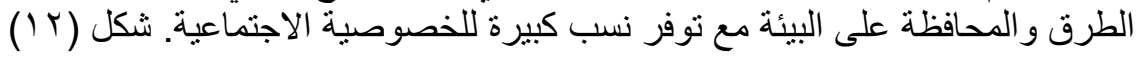




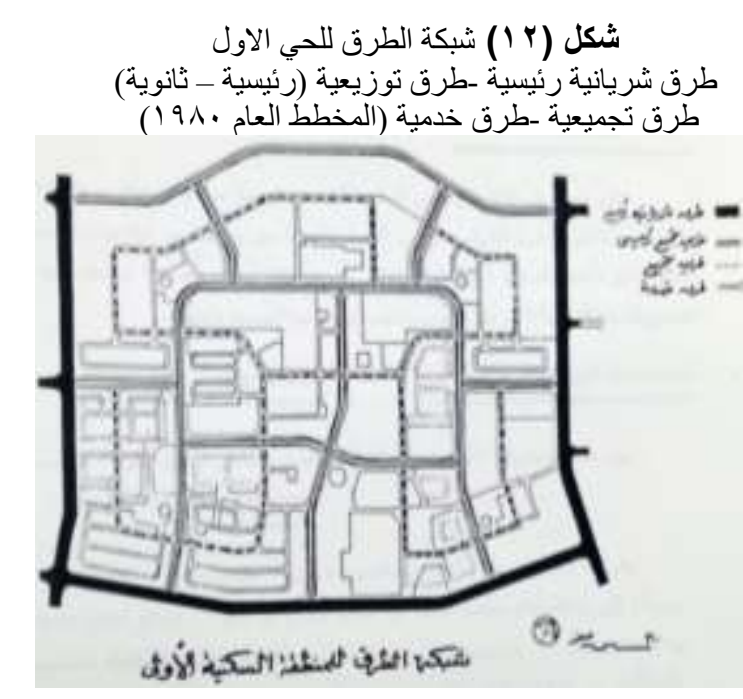

(التقرير الأول • (1999)

شكل (r 1 ) شبكة الطرق الإقليمية و المحلية و السكك

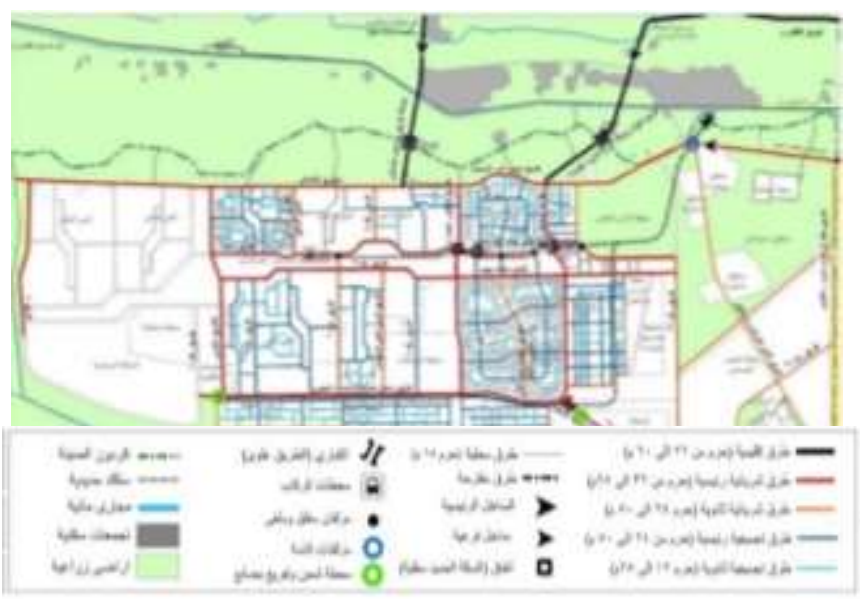

شكل (؛ 1) شبكة الطرق الرئبسية والمحلية المنفذة للحي

الاول بالمدينة (الباحث) الرنشة

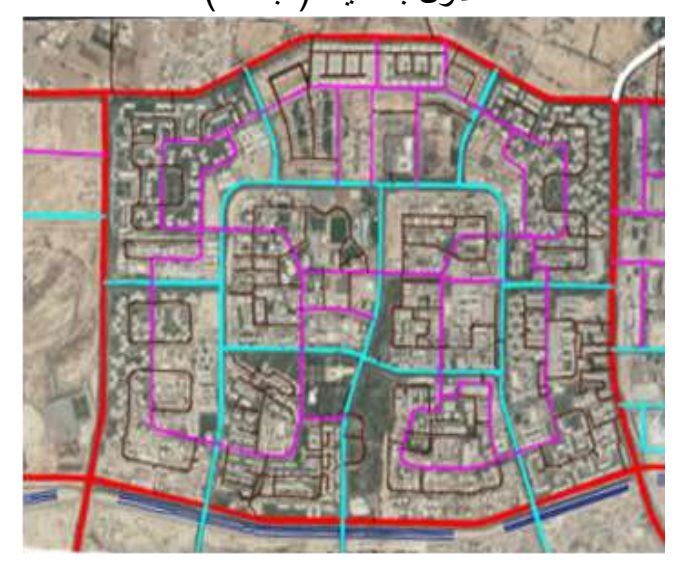

\begin{tabular}{|c|c|}
\hline ـ كم - & الثريانية الرئيسية \\
\hline 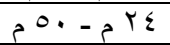 & التوزيعية الرئيسبة \\
\hline 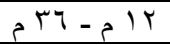 & التوزيعية الثانوية \\
\hline 11 & طرق تجميعية \\
\hline
\end{tabular}

شكل (11) شبكة الطرق الإقليمية

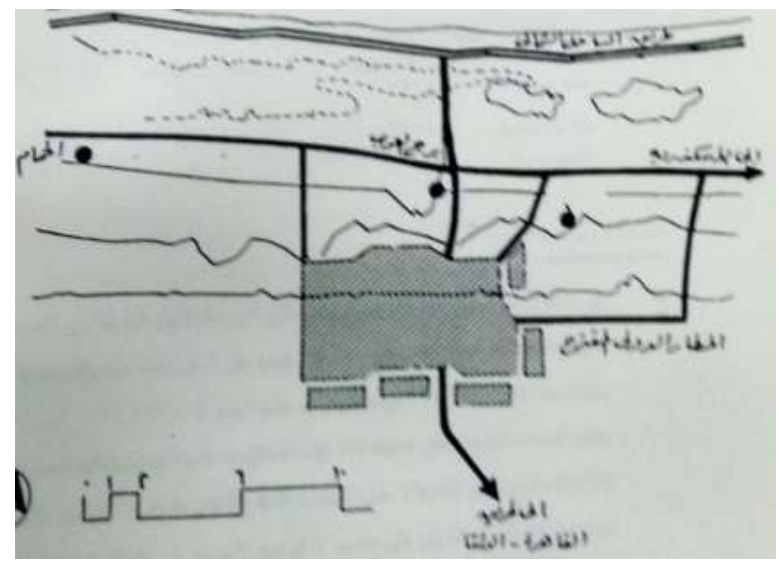

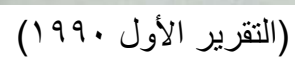

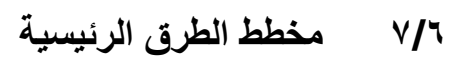

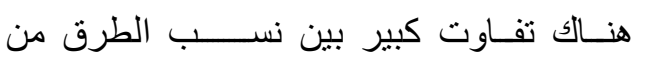

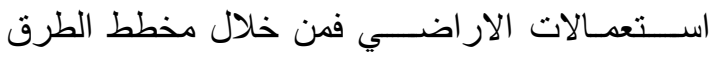

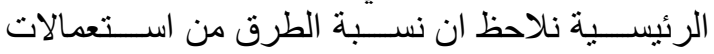

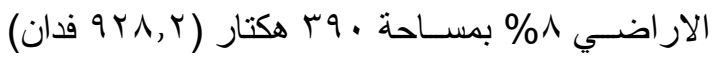

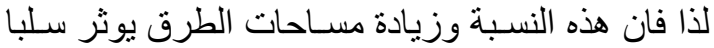

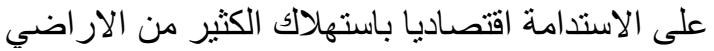

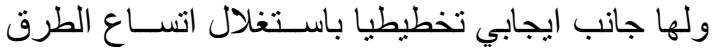
لعمل ممرات للمشاة و الدر اجات وزيادة تشجير الطرق. ويوضــــ مخطط الطرق الر اهنة تكامل التخطيط

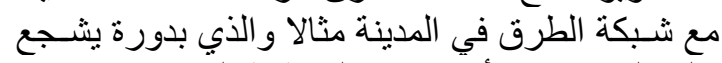

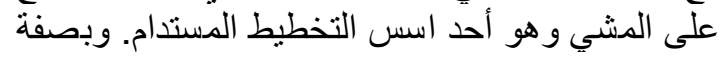

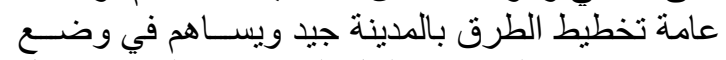
رؤية مستدامة لمنظومة النقل الحضري جائة بالمدينة. شكل

\section{Y.1. نسبة تنفيذ للشبكة حتى V/V}

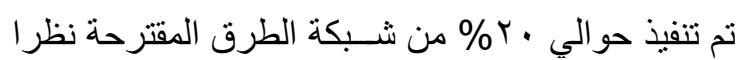

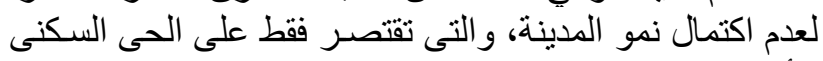

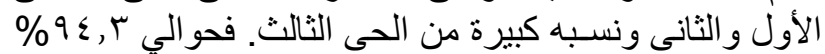

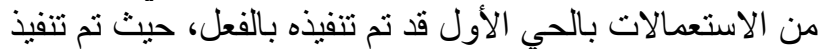

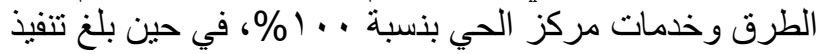

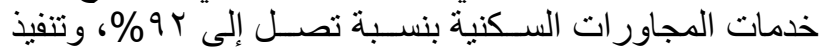

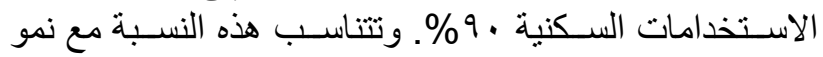
المدينة ومع ب مع الكثافة السكانية الموجودة.

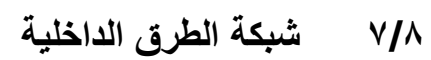

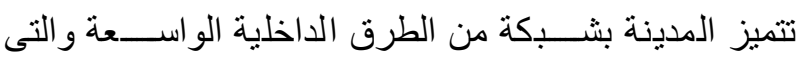

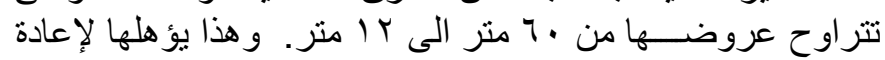


تخطيطها مسـتقبلا بما يتناسـب مع اسـس وقو اعد الإسـتدامة بعمل مسـار ات خاصـة للمثــاة واخرى للار اجات مع زر اعة الجزر بالأشجار و المساحات الخضر اء.

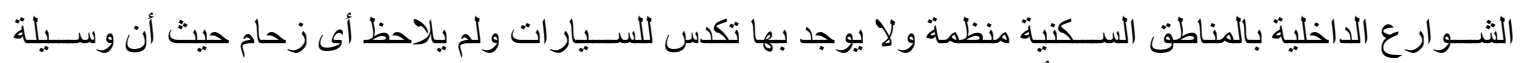

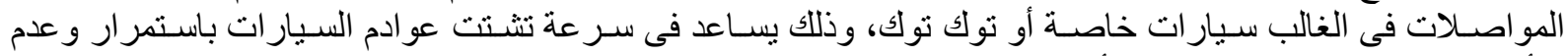

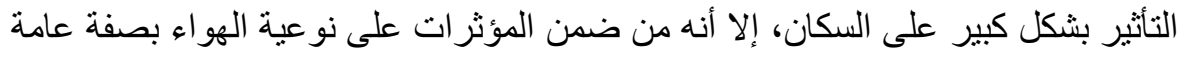

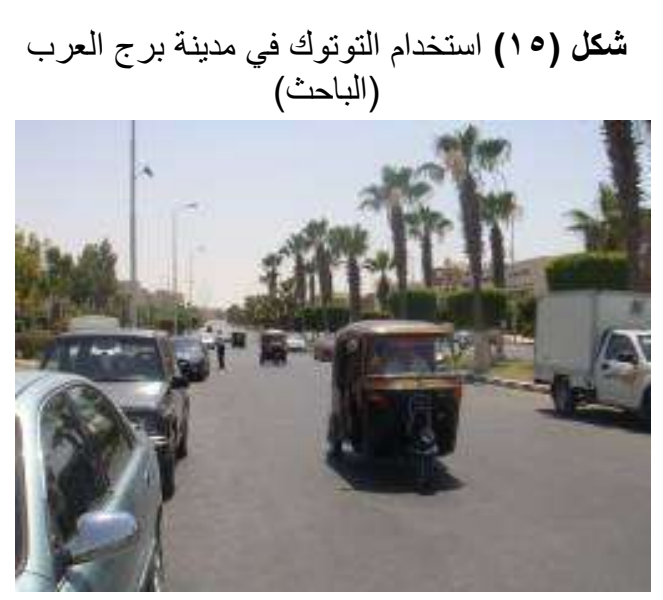

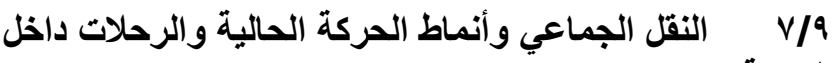
المدينة يوجد موقف نقل جماعى إقليمى مع الموقف الوحيد للسيرفس الإنس

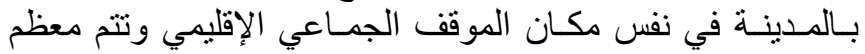

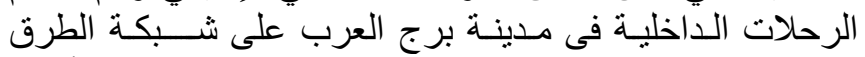

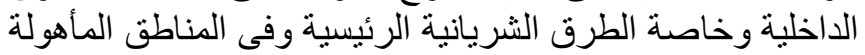

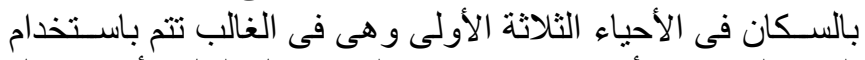

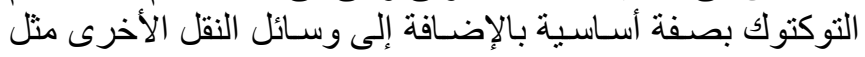

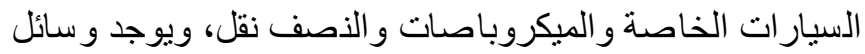

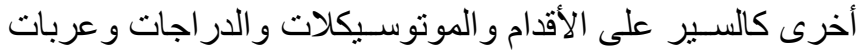

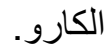

\begin{tabular}{|c|c|c|c|c|c|c|c|c|}
\hline \multicolumn{9}{|c|}{ 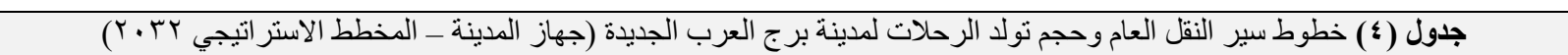 } \\
\hline $019 \leq 9$ & $\% \wedge$. & داخلية & \multirow[t]{3}{*}{ الرحملات نولد } & \multirow[t]{3}{*}{ المجموع } & $\begin{array}{l}1 \\
1 .\end{array}$ & 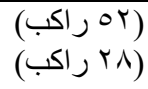 & الإقليمى & \multirow[t]{3}{*}{ خطوط سبر } \\
\hline $1 \leqslant V T V$ & $\%$ \%. & خارجية & & & 7 & 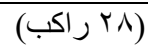 & الجماعى & \\
\hline 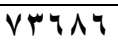 & $\% 1 \ldots$ & الاجمالى & & & & & 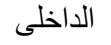 & \\
\hline
\end{tabular}

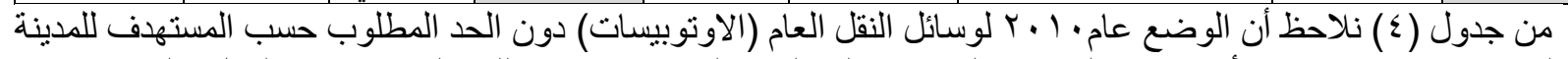

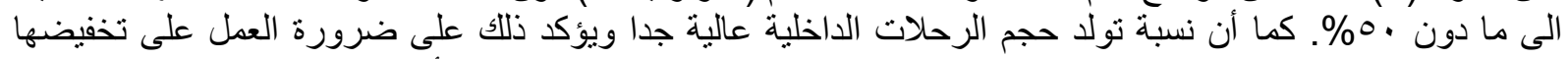

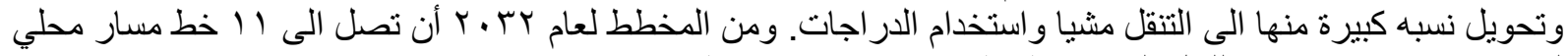
للانوبيس ومجمع سيرفس للنقل العام وخط قطار سريع وثناثلث محطات.

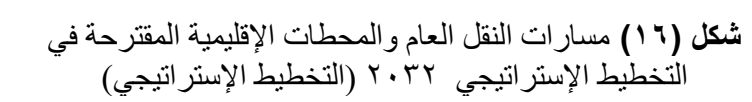

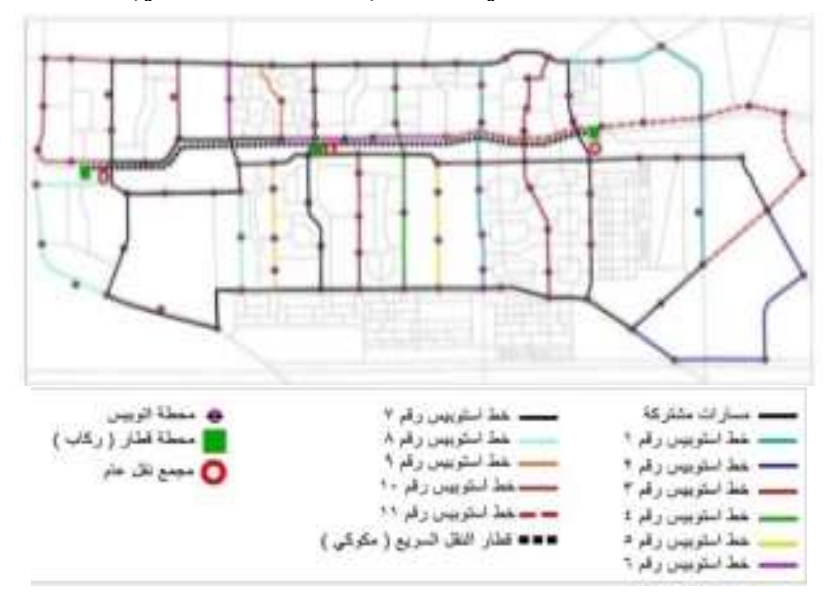

النقل الجماعي الاقليمي للمدينة يتواكب مع الكثافة

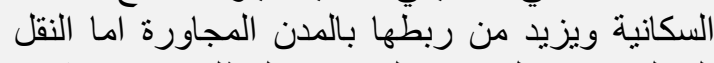

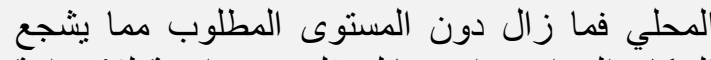

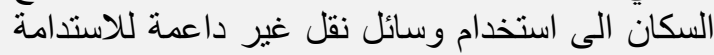
كالسيار ات الخاصة و التوكتوك ولك. عدم تنظيم هذا الكم الهائل من التوكتو كأت تسبب في في حدوث تكدس و اختناقات شديدة بشبكة الطرق الداخلية بالمدينة

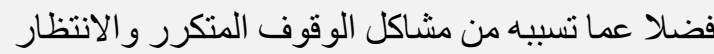

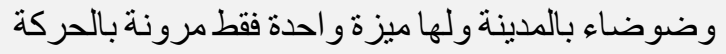

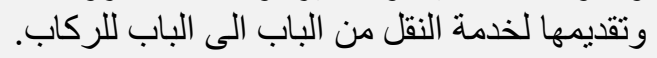

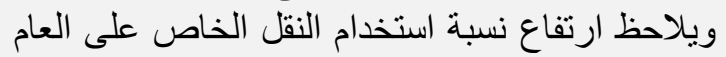

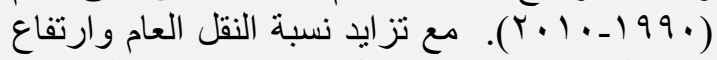

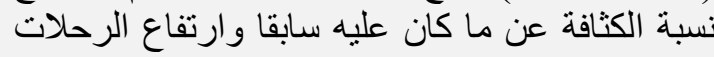

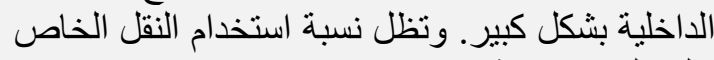
على العام مرتفعة.

V المساحات الخضراء ومنظومة النقل الحضري:

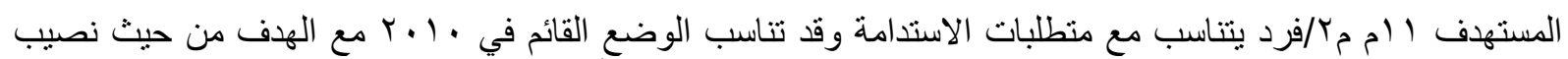

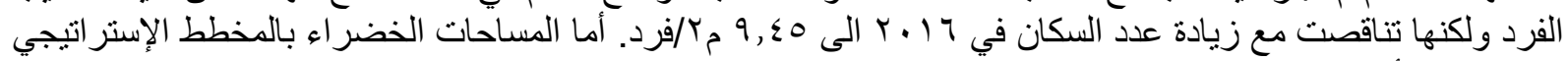

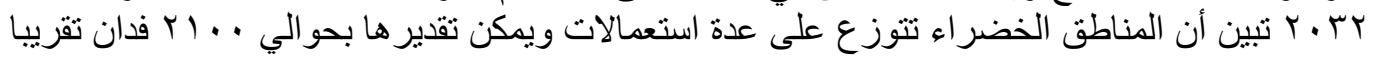




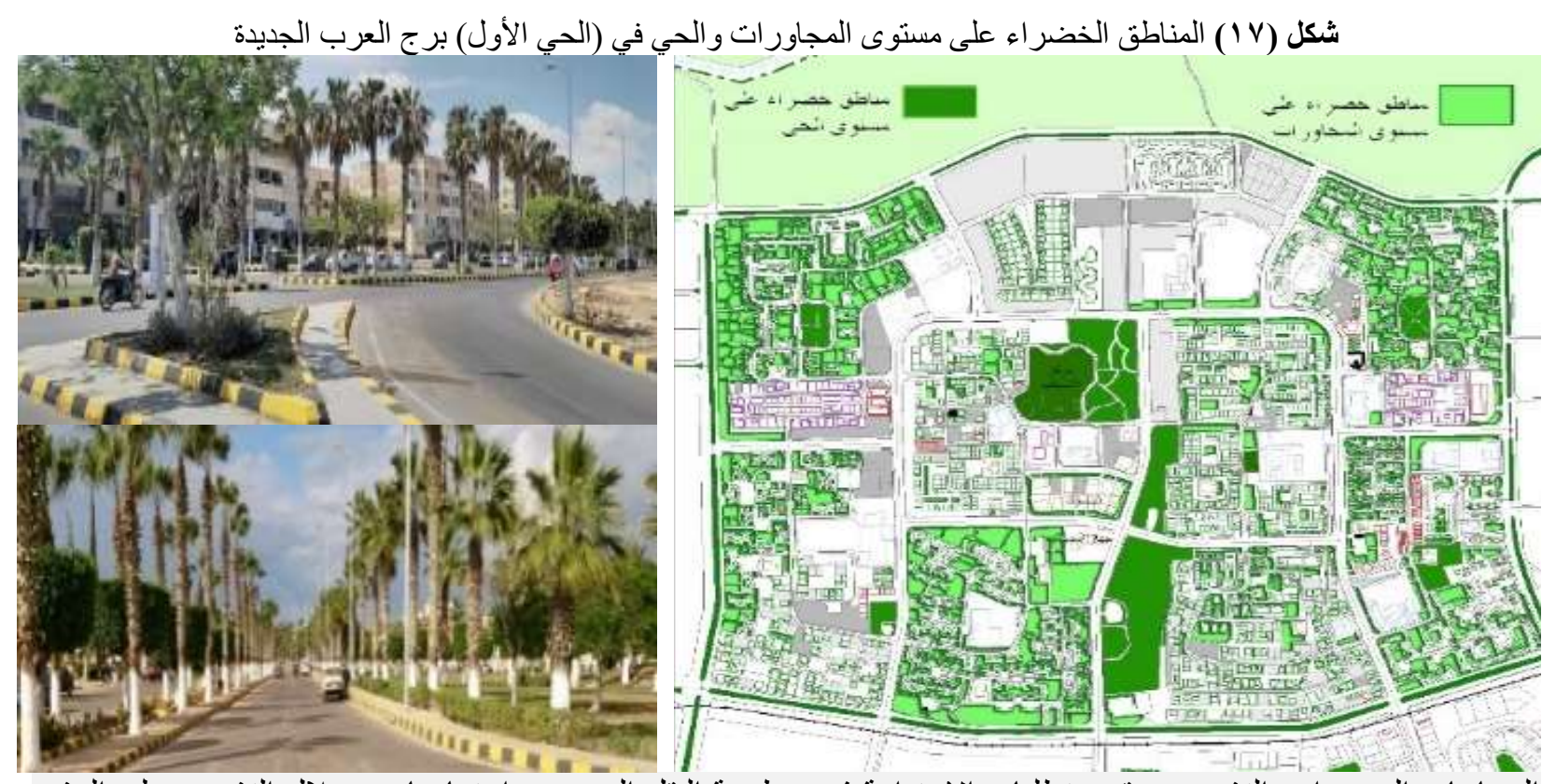

المساحات الخضر اءو والتشجير يحقق منطلبات الاستدامة في منظومة النقل الحضري اجتماعيا من خلال التشجيع على المشي

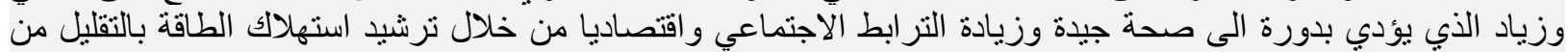

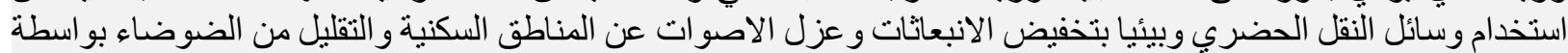

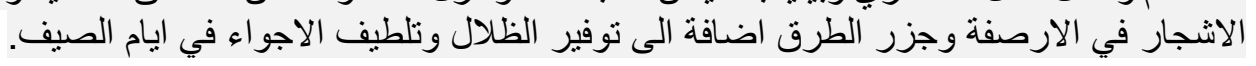

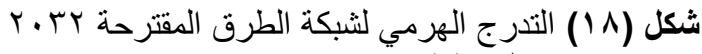

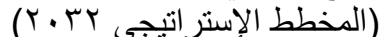

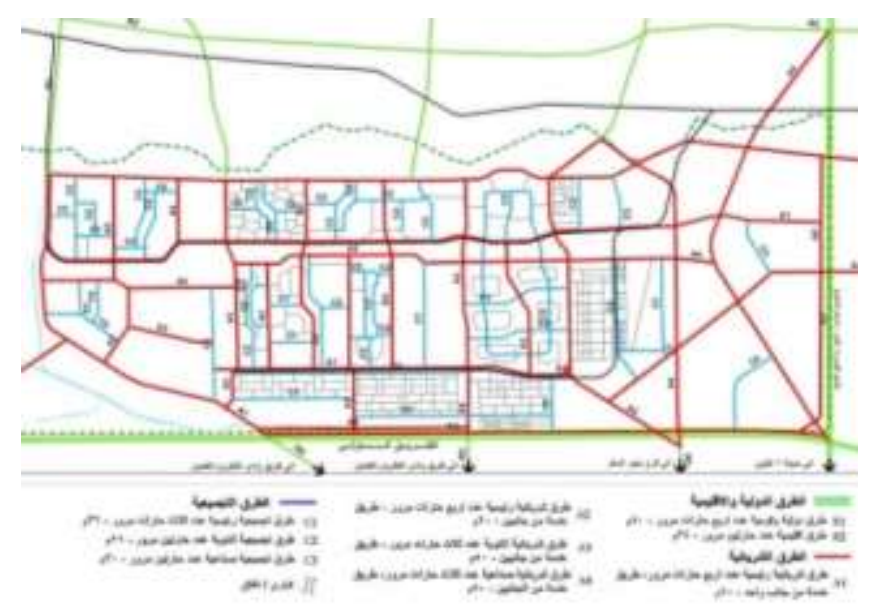

\section{V/I}

تتسم المخططات الاستراتيجية بمسارات

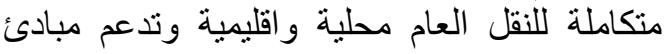

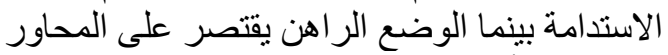

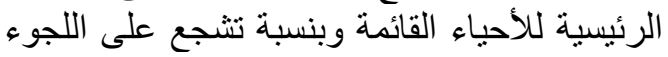

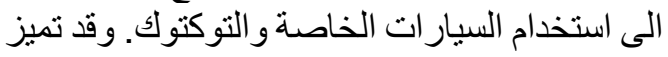

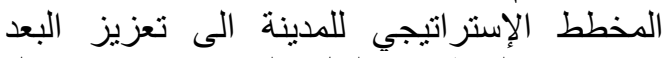

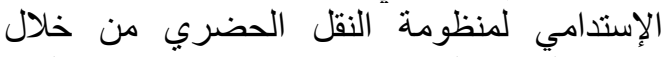
تطوير الطرق الرئيسية واضافة طرق الطية جديدة اقليميا

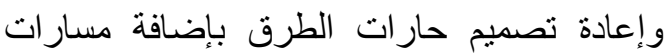

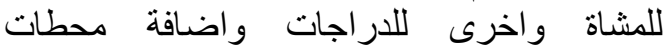
ومسارات جديدة والتوصية بتعزيز وسائل النقل

الحضري صديقة للبيئة. شكل (1) 


\section{^ 1 النتائج والتوصيات \\ من اهم اسس النقل الحضري المستدام}

- ـ تخطيطيا (التوجيه، تصميم الثوارع - تخطيط مدمج - الكثافة العالية - توفير الخدمات - المساحات الخضر اء).

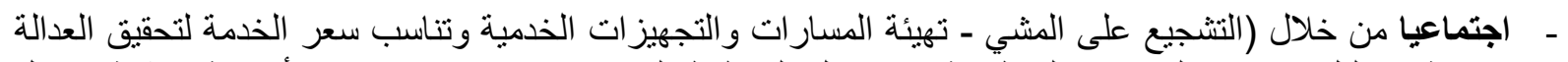

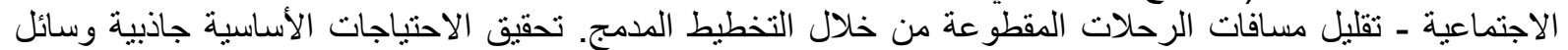

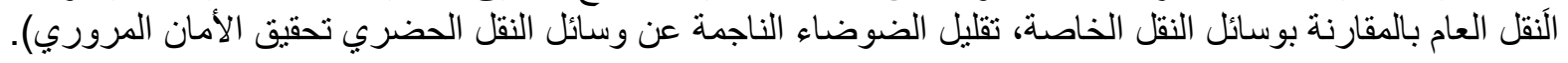
ـ ـ اقتصاديا من خلال (تقليل معدلات استخدام السيارات، توفير مسارات وخدمات لازمة لاستخدام الدرجات، و إعطاء

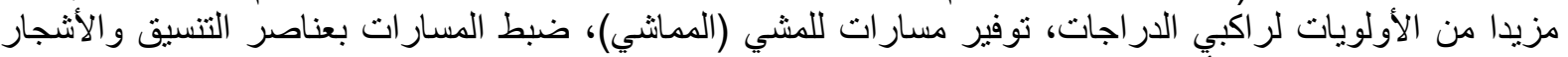

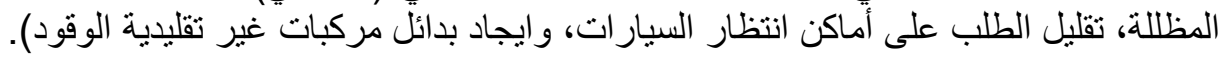
- ـ بيئيا من خلال (الوصول للحد الأدنى من الانبعاثات الناجمة عن الوقود المستخدم بالنقل الحضري واستخدام وسائل نقل صديقة للبيئة لتخفيف التلون (لتون).

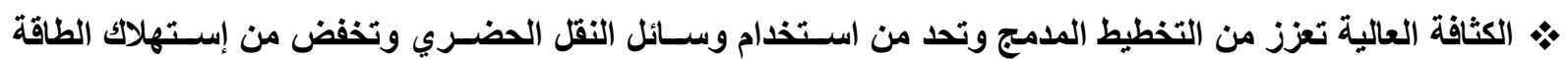

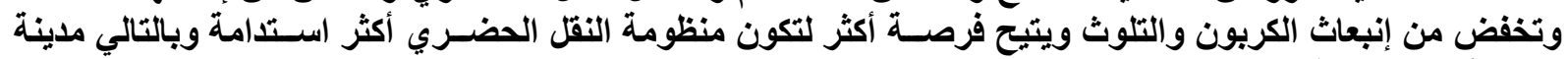
جليدة أكثر إستذامنة.

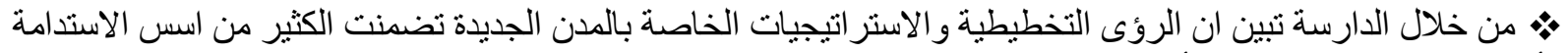

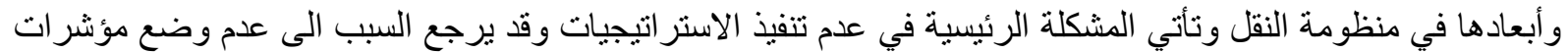

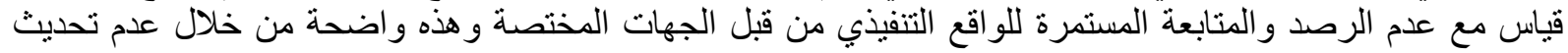

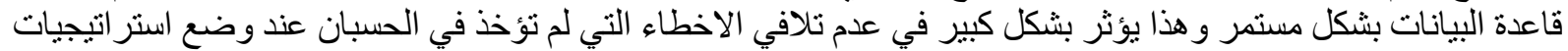

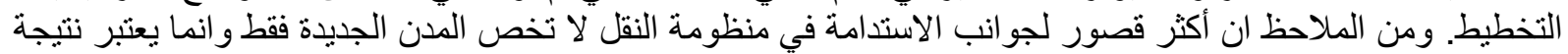

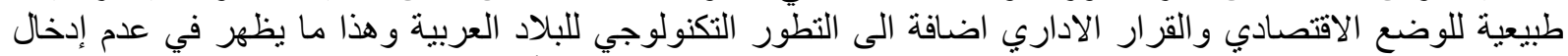

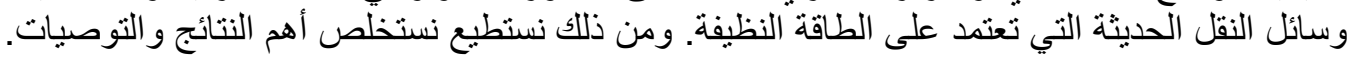

N/1

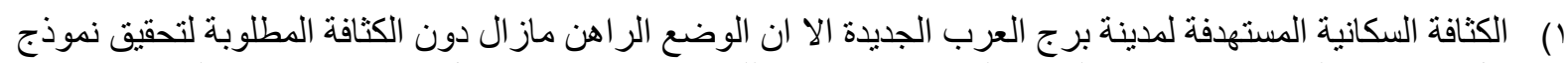

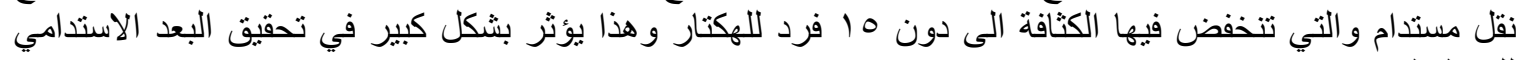

للتخطيط.

r) من إيجابيات التخطيط للمدن الجديدة هي التوجيه ومر اعاة تصميم الطرق و المحاور الرئيسية في الاتجاهات الثمالية

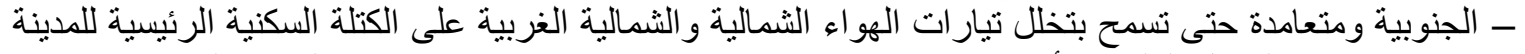

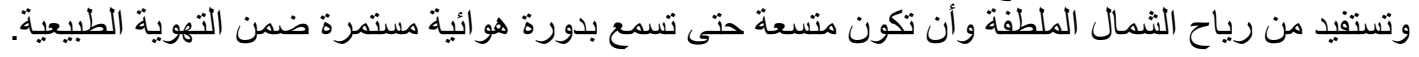

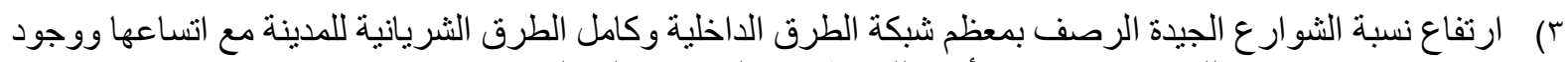

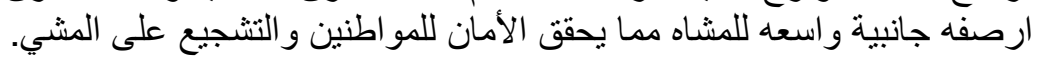

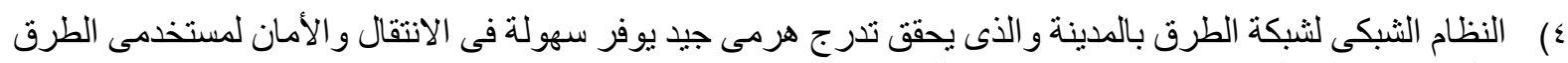
و المحافظة على البيئة مع توفر نسب كبيرة للنصوية للنصوصية الاجتماعية.

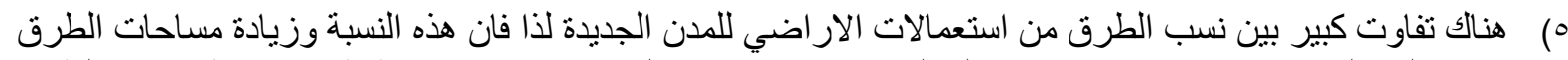

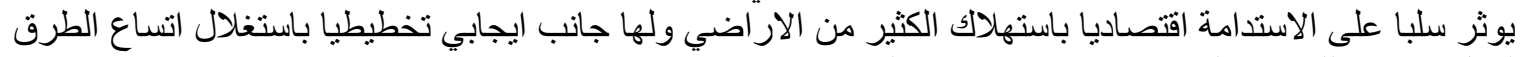

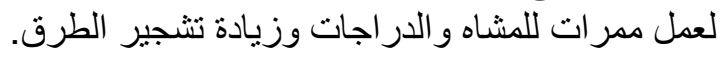

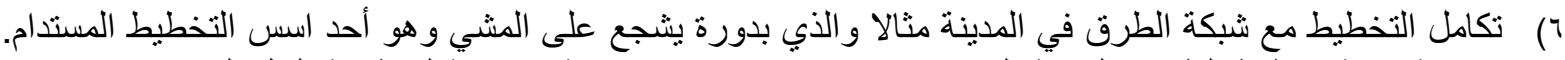

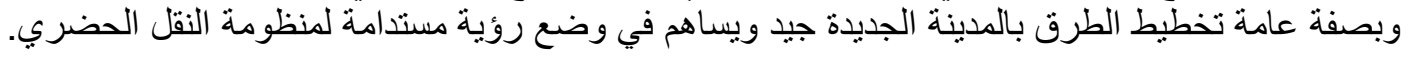

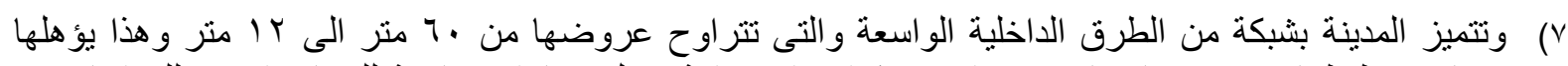

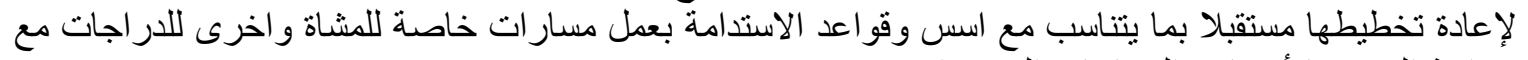

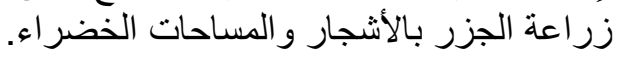


الشوارع الداخلية بالمناطق السكنية منظمة ولا يوجد بها تكدس للسيارات ولم يلاحظ أى زحام حيث أن وسيلة

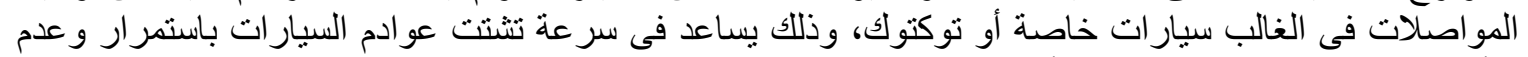

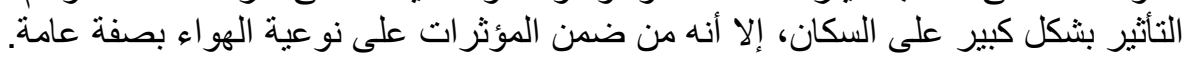

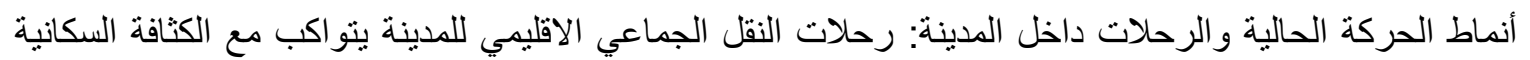

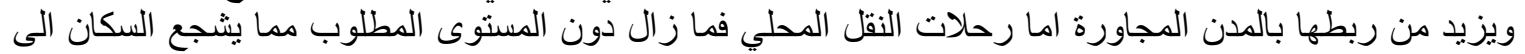
استخدام وسائل نقل غير داعمة للاستدامة كالسيار ات الخاصنة و التوكتوك.

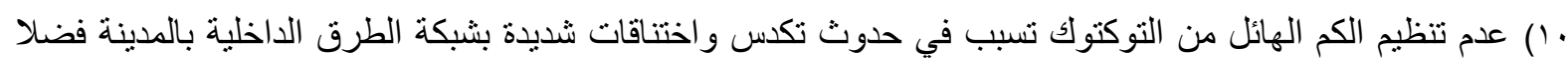

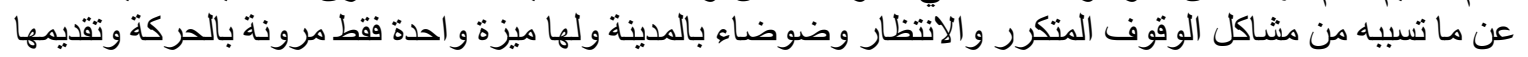
لخدمة النقل من الباب الى من الباب للركاب.

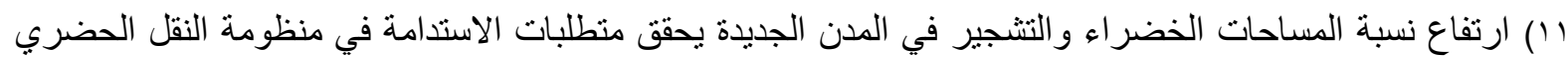

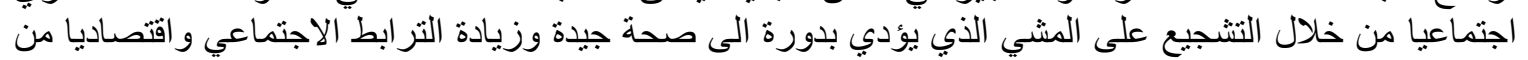

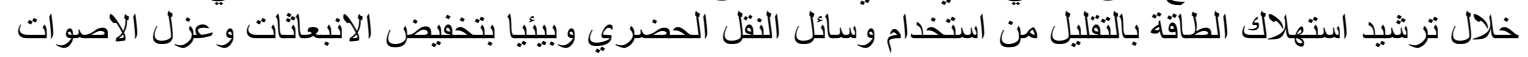

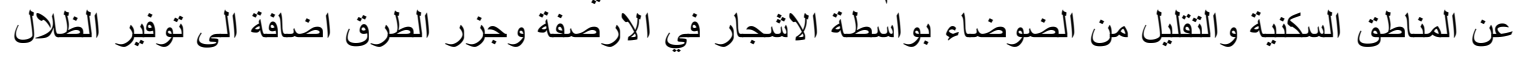
وتلطيف الاجو اء في ايام الصيف. والفيل

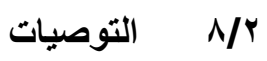

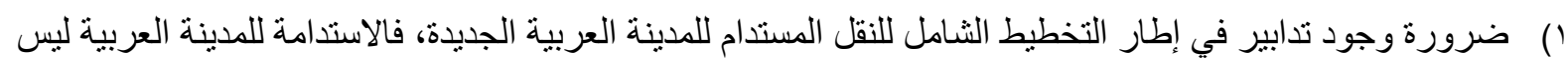

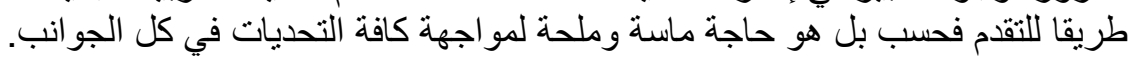

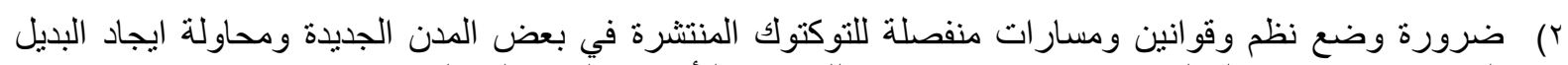

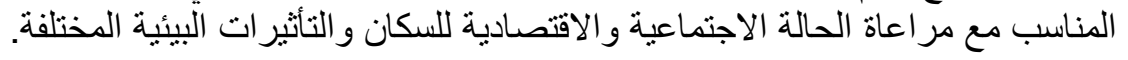

r) ضرورة ادخال وسائل نقل صديقة للبيئة وتدعم الاستدامة وتستخدم الطاقة الكهربائية بدلا من المو اد البترولية المختلفة.

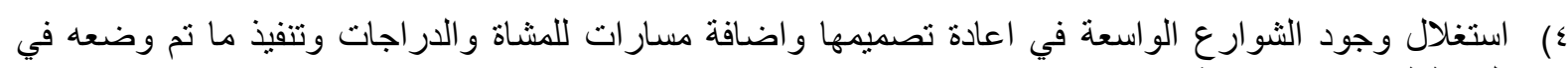
المخططات الاسنر اتيجية.

ه) ضرورة التقليل من حجم الرحلات من خلال نوفير الخدمات على كافة المستويات (المجاورة ـ الحي ـ المركز)

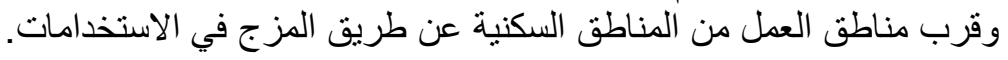

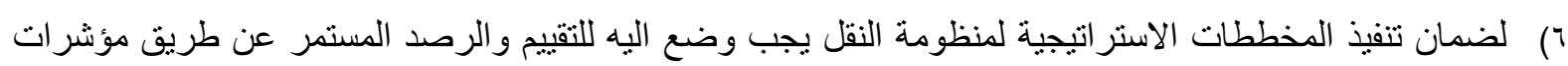
اداء و اضحة.

V تنفيذ ونوفير كافة الخدمات في إطار المجاورة السكنية لتحقيق تخطيط مدمج ومناطق سكنية مشجعه للمشي و التقليل من استخدام وسائل النقل الخاصية فئة

\section{/ المراجع}

\section{references}

\section{1/9 المراجع العربية}

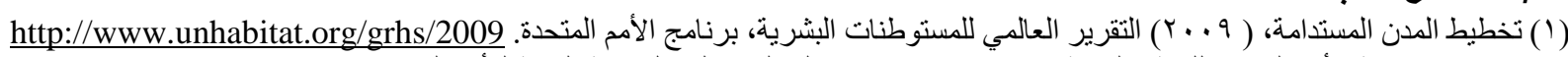

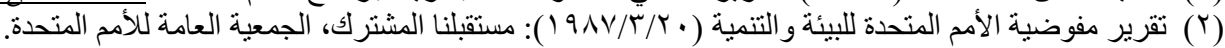

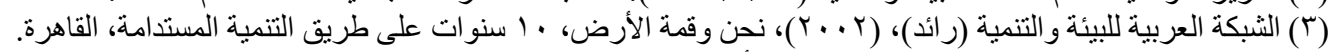

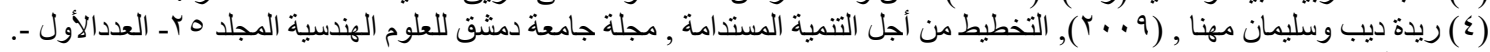

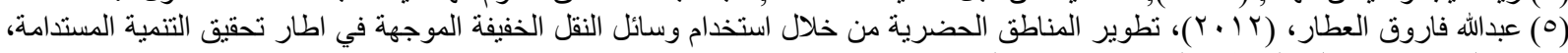

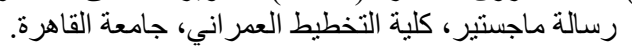

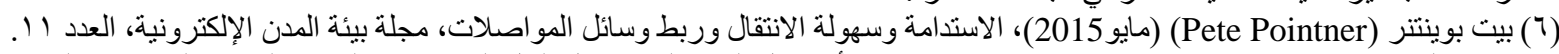

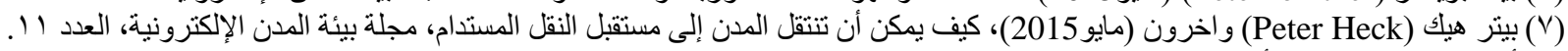

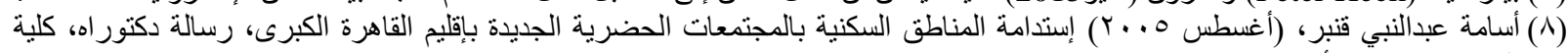
الهنسة، جامعة الأزهر. 


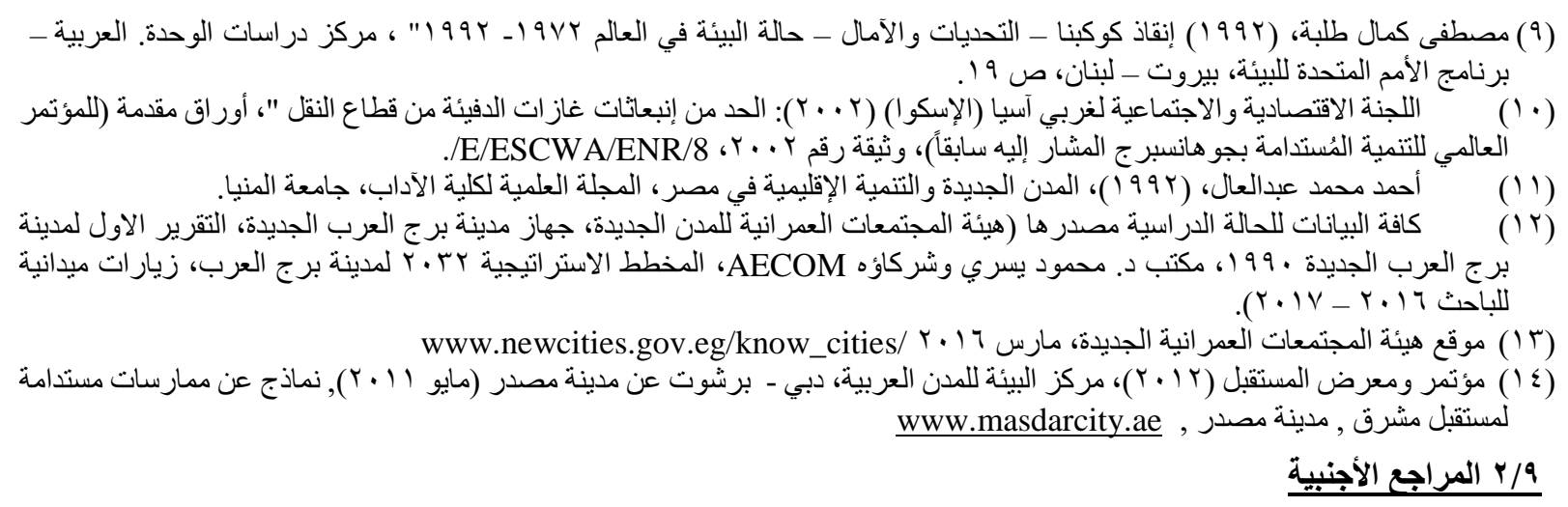

(15) International Energy Agency, A tale of renewed cities. Retrieved (February IV, Y. 10), from International Energy Agency: available at: http://www.iea.org/publications/freepublications/publication/Renewed_Cities_WEB.pdf.

(16) "17 Goals to Transform Our World" at: (20/1/2017). Available at: http://www.un.org/sustainabledevelopment/en.

(17) Sustainable_urban_planning, at: (11/8/2015), available at: https://en.wikipedia.org/wiki/Category:

(18) Mike Jenks and Nicola Dempsey (2005), Future Forms and Design for Sustainable Cities.

(19) Jackie Teed and Patric Condon, (2005), sustainable urban landscapes Neighborhood pattern typology, The University of Br British Columbia.

(20) Cliff Moughtin, (2003), Urban Design, Street and Square, 3 Edition.

(21) Richard Rogers \& Philip Gumuchdjian (1997): cities for a small planet ,England, Butler and Tanner Ltd, Frome.

(22) "Sustainable Transportation for-sustainable cities". At: 20/3/2017 Available at: http://www.envirocitiesmag.com/articles/sustainable-transportation-for-sustainable-cities/the-A-S-I-approach.php.

(23) "Unhabitat for Better Urban Future". at: 20/1/2017. Available at: http://unhabitat.org/un-habitat-for-thesustainable-development-goals/11-2-transport-system/.

(24) Pirita Lindholm. (30/8/2004). "Trends and Indicators for Monitoring the EU Thematic Strategy on Sustainable Development of Urban Environment". EU: EU-Commission, Consortium members. Parts of the background paper has been written by Michal Arend and Marie Fegeler. Tissue-Consortium.

(25) The Centre for Sustainable Transportation in Toronto, (September1997) Canada. "Annex 1: Sustainable Transportation - Definitions".

(26) "Pedestrianisation" at: (9/7/2003). Available at: www.info.gov.hk/td/eng/transport/ped_menu.html.

(27) David Rousseau, Co-Chair. Urban Environmental Institute. (oct 22, 2002). "Resource Guide for Sustainable Development in an Urban Environment". USA: Seattle, WA, Sustainability Technical Review Committee.

(28) Essam El-hennawi and M. Hasmi and C.L Ndiokwere, (1984). "A Study of Heavy Metal Pollution from Motor Vehicle Emissions and its effects on Roadside Soil Vegetation and crops in Nigeria". Environmental pollution, Series B, vol. 7.

(29) Sustainable Development Goals, at. (3/1/2016) at: http://www.un.org/sustainabledevelopment/ar/cities Available

(30) the sustainability city at :(2015). Available at: http://www.masdarcity.ae/mobile/ar/30/sustainability-andthe-city/.

(31) Masdar City Abu Dhabi, (2009), Presentation at AGS Annual Meeting.

(32) Azhar Othman, (26 June 2012), Perbadanan Putrajaya, Seminar ke arah Bandaraya: Implementasi Teknologi Hijau dan Pembangunan Mampan di kawasan Majlis Bandaraya Seremban .

(33) Putrajaya Green City 2025, ( November, 2012) ,Baseline and Preliminary Study, Revised Edition, Universiti Teknologi Malaysia ...

(34) Sino- Singapore Tianjin Eco-City, November (2009): A Case Study of an Emerging Eco-City in China, THE World Bank Rebort.

(35) Herbert Girardet , (2004), Cities, People, Planet Liveable Cities for a Sustainable World, Herbert Girardet, published by Wiley-Academy. 


\title{
Principles for Sustainable Urban Transportation for new Arabian Cities
}

\begin{abstract}
Arab cities are facing problematical urban situations. One of the recent concerns of sustainabitly is the essential need to resolve the mobility issues in the urban transport system . this paper aims to establish main principles as a base for sustainable transport and prioritize them for the new arab city regarding its current situation . the significance of this paper is to examine the obstacles in achieving sustainability in urban transport system that avert the achievement of strategic goals and future visions.

The problem in most arab cities is the mobility strategies and rapid changes in sustainable urban transport planning. The methodology used in this paper is the comparative inductive analytical method, which discusses the basic concepts of sustainability and its principles. The challenges facing the urban transport system in the palnning of the new arab city . as well as the paper is studying international experience to extract the sustainable criteria of urban transport system. its importance, , its role in sustainable planning and then analyzing the palnning vision as well as the current state of urban transport in the new Egyptian cities of new borg el arab
\end{abstract}

Keywords: Urban transport, sustainability, Arab city, planning new cities 